\title{
Mapping daily evapotranspiration at field to continental scales using geostationary and polar orbiting satellite imagery
}

\author{
M. C. Anderson ${ }^{1}$, W. P. Kustas ${ }^{1}$, J. M. Norman ${ }^{2}$, C. R. Hain ${ }^{3}$, J. R. Mecikalski ${ }^{4}$, L. Schultz ${ }^{4}$, M. P. González-Dugo ${ }^{5}$, \\ C. Cammalleri ${ }^{6}$, G. d'Urso ${ }^{7}$, A. Pimstein ${ }^{8}$, and F. Gao ${ }^{9}$ \\ ${ }^{1}$ US Dept of Agriculture, Beltsville, MD, USA \\ ${ }^{2}$ Dept. of Soil Science, University of Wisconsin-Madison, Madison, WI, USA \\ ${ }^{3}$ I.M. Systems Group at NOAA/NESDIS, Camp Springs, MD, USA \\ ${ }^{4}$ Dept. Atmospheric Sciences, University of Alabama-Huntsville, Huntsville, AL, USA \\ ${ }^{5}$ IFAPA Andalusian Agriculture and Fisheries Dept, Córdoba, Spain \\ ${ }^{6}$ Dept. Civil, Environ. and Aerosp. Eng., Università degli Studi di Palermo, Palermo, Italy \\ ${ }^{7}$ Dept. Agricultural Engineering and Agronomy, University of Naples Federico II, Naples, Italy \\ ${ }^{8}$ Dept. of Fruit Production and Enology, Pontificia Universidad Católica de Chile, Santiago, Chile \\ ${ }^{9}$ NASA Goddard Space Flight Center and Earth Resources Technology Inc., MD, USA
}

Received: 16 July 2010 - Published in Hydrol. Earth Syst. Sci. Discuss.: 23 August 2010

Revised: 4 January 2011 - Accepted: 6 January 2011 - Published: 21 January 2011

\begin{abstract}
Thermal infrared (TIR) remote sensing of landsurface temperature (LST) provides valuable information about the sub-surface moisture status required for estimating evapotranspiration (ET) and detecting the onset and severity of drought. While empirical indices measuring anomalies in LST and vegetation amount (e.g., as quantified by the Normalized Difference Vegetation Index; NDVI) have demonstrated utility in monitoring ET and drought conditions over large areas, they may provide ambiguous results when other factors (e.g., air temperature, advection) are affecting plant functioning. A more physically based interpretation of LST and NDVI and their relationship to subsurface moisture conditions can be obtained with a surface energy balance model driven by TIR remote sensing. The Atmosphere-Land Exchange Inverse (ALEXI) model is a multi-sensor TIR approach to ET mapping, coupling a two-source (soil + canopy) land-surface model with an atmospheric boundary layer model in time-differencing mode to routinely and robustly map daily fluxes at continental scales and 5 to $10-\mathrm{km}$ resolution using thermal band imagery and insolation estimates from geostationary satellites. A related algorithm (DisALEXI) spatially disaggregates ALEXI fluxes down to finer spatial scales using moderate resolution TIR imagery from polar orbiting satellites. An overview of this modeling approach is presented, along with strategies
\end{abstract}

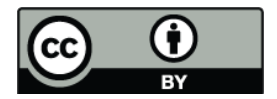

Correspondence to: M. C. Anderson (martha.anderson@ars.usda.gov) for fusing information from multiple satellite platforms and wavebands to map daily ET down to resolutions on the order of $10 \mathrm{~m}$. The ALEXI/DisALEXI model has potential for global applications by integrating data from multiple geostationary meteorological satellite systems, such as the US Geostationary Operational Environmental Satellites, the European Meteosat satellites, the Chinese Fen-yung 2B series, and the Japanese Geostationary Meteorological Satellites. Work is underway to further evaluate multi-scale ALEXI implementations over the US, Europe, Africa and other continents with geostationary satellite coverage.

\section{Introduction}

Water lost to the atmosphere through evapotranspiration (ET) has the effect of cooling the Earth's surface. Land-surface temperature (LST), as mapped using thermal-infrared (TIR) band data, is therefore a valuable remote indicator of both ET and the surface moisture status (Moran, 2003). In partially vegetated landscapes, depletion of water from the soil surface layer $(0-5 \mathrm{~cm})$ causes the soil component of the scene to heat rapidly. Moisture deficiencies in the root zone (down to 1-2 $\mathrm{m}$ depth) lead to stomatal closure, reduced transpiration, and elevated canopy temperatures, which can be effectively detected from space in the thermal wavebands (Anderson et al., 2007b). Unlike standard water balance approaches to modelling ET, TIR remote sensing provides diagnostic

Published by Copernicus Publications on behalf of the European Geosciences Union. 
Table 1. Examples of current and future satellite-based TIR imaging system, along with characteristic spatial and temporal resolutions (table adapted from Hook, http://landportal.gsfc.nasa.gov/ Documents/ESDR/Temp-Emissivity_Hook_whitepaper.pdf).

\begin{tabular}{lllll}
\hline $\begin{array}{l}\text { Pixel } \\
\text { scale }\end{array}$ & $\begin{array}{l}\text { Spatial } \\
\text { resolution }\end{array}$ & $\begin{array}{l}\text { Temporal } \\
\text { resolution }\end{array}$ & $\begin{array}{l}\text { Current } \\
\text { sources* }\end{array}$ & $\begin{array}{l}\text { Future } \\
\text { sources* }\end{array}$ \\
\hline Coarse & $5-20 \mathrm{~km}$ & $15 \mathrm{~min}$ & $\begin{array}{l}\text { GOES } \\
\text { MSG }\end{array}$ & $\begin{array}{l}\text { GOES } \\
\text { MSG } \\
\end{array}$ \\
& & & AIRS & CrIS \\
\hline Moderate & $1 \mathrm{~km}$ & Daily & $\begin{array}{l}\text { MODIS } \\
\text { AVHRR }\end{array}$ & VIIRS \\
& & & AVHRR \\
& & & ATSR & \\
\hline Fine & $60-120 \mathrm{~m}$ & $\begin{array}{l}\text { Once every } \\
\text { 5-16 days }\end{array}$ & $\begin{array}{l}\text { Landsat } \\
\text { ASTER }\end{array}$ & LDCM \\
& & HyspIRI \\
\hline
\end{tabular}

* GOES (Geostationary Operational Environmental Satellite), MSG (Meteosat Second Generation), AIRS (Atmospheric Infrared Sounder), MODIS (Moderate Resolution Imaging Spectroradiometer), AVHRR (Advanced Very High Resolution Radiometer), ATSR (Along Track Scanning Radiometer), ASTER (Advanced Spaceborne Thermal Emission and Reflection Radiometer), CrIS (Cross-track Infrared Sounder), VIIRS (Visible/Infrared Imager Radiometer Suite), LDCM (Landsat Data Continuity Mission), HyspIRI (Hyperspectral-Infrared Imager)

assessments of surface moisture conditions without the need for ancillary information about precipitation or soil texture and moisture holding capacity, making this methodology particularly useful for applications in data-poor regions of the world. To exploit this potential, many TIR-based ET retrieval algorithms have been developed over the past few decades to facilitate routine monitoring of water usage/availability and regional food security (see recent reviews by Courault et al., 2005; Kalma et al., 2008).

Hydrologic applications in agriculture and water resource management require ET/soil moisture information over a range of temporal and spatial resolutions, from hourly to monthly timesteps and at field to global scales. Unfortunately, no single satellite system affords global coverage in the thermal wavebands at both high spatial and high temporal resolution. Several current and future TIR imaging systems are summarized in Table 1, providing data at coarse spatial and high temporal resolution from geostationary platforms (sub-hourly imagery at $3-10-\mathrm{km}$ resolution), moderate resolution daily imaging from polar orbiting systems such the Moderate Resolution Imaging Spectroradiometer (MODIS) and the Advanced Very High Resolution Radiometer (AVHRR; both daily at $1 \mathrm{~km}$ ), and relatively high spatial resolution but infrequent temporal information from narrowswath polar systems like Landsat (16-day revisit at 60 to 120-m resolution).

In this paper we describe a technique for fusing ET information derived from multiple wavebands and satellites with different revisit cycles and pixel sizes to map hourly/daily ET at spatial resolutions of $10 \mathrm{~km}$ using geostationary data over continents down to $10-30 \mathrm{~m}$ over localized regions, cor- responding to the shortwave multi-band imaging resolutions achievable with the Advanced Spaceborne Thermal Emission and Reflection Radiometer (ASTER) and Landsat. Multiscale ET products are generated with a physically based inverse model of Atmosphere-Land Exchange (ALEXI) and an associated flux disaggregation technique (DisALEXI), a modelling framework for synthesizing multi-scale, multiplatform TIR imagery into useful end-products for operational monitoring of drought and evaporative water loss over a range in spatiotemporal scales.

Here we present an overview of the modelling algorithm, and describe several current international projects involving drought monitoring, irrigation management and hydrologic decision support in Europe, Africa and the United States. Plans to apply ALEXI globally, and to integrate microwave soil moisture information to improve temporal sampling, are described under future work.

\section{Methodology}

The ALEXI/DisALEXI modelling system can be applied to any of the satellite-based TIR data streams listed in Table 1 , depending on the resolution required by a given application. Here we provide brief overview of this modelling framework, and introduce image sharpening and fusion techniques that have been developed to improve spatiotemporal resolution in ET products by combining information from multiple satellites and wavebands.

\subsection{Mapping evapotranspiration}

\subsubsection{ALEXI}

The ALEXI surface energy balance model (Anderson et al., 1997, 2007b, c; Mecikalski et al., 1999) was specifically designed to minimize the need for ancillary meteorological data while maintaining a physically realistic representation of land-atmosphere exchange over a wide range in vegetation cover conditions. It is one of few diagnostic land-surface models designed explicitly to exploit the high temporal resolution afforded by geostationary satellites.

Surface energy balance models estimate ET by partitioning the energy available at the land surface $(\mathrm{RN}-G$, where $\mathrm{RN}$ is net radiation and $G$ is the soil heat conduction flux, in $\mathrm{W} \mathrm{m}^{-2}$ ) into turbulent fluxes of sensible and latent heating $\left(H\right.$ and $\lambda E$, respectively, $\mathrm{W} \mathrm{m}^{-2}$ ):

$\mathrm{RN}-G=H+\lambda E$.

where $\lambda$ is the latent heat of vaporization $\left(\mathrm{J} \mathrm{kg}^{-1}\right)$ and $E$ is ET $\left(\mathrm{kg} \mathrm{s}^{-1} \mathrm{~m}^{-2}\right.$ or $\left.\mathrm{mm} \mathrm{s}^{-1}\right)$. Surface temperature is a valuable metric for constraining $\lambda E$ because varying soil moisture conditions yield a distinctive thermal signature associated with the soil and canopy components of the imaging scene. 


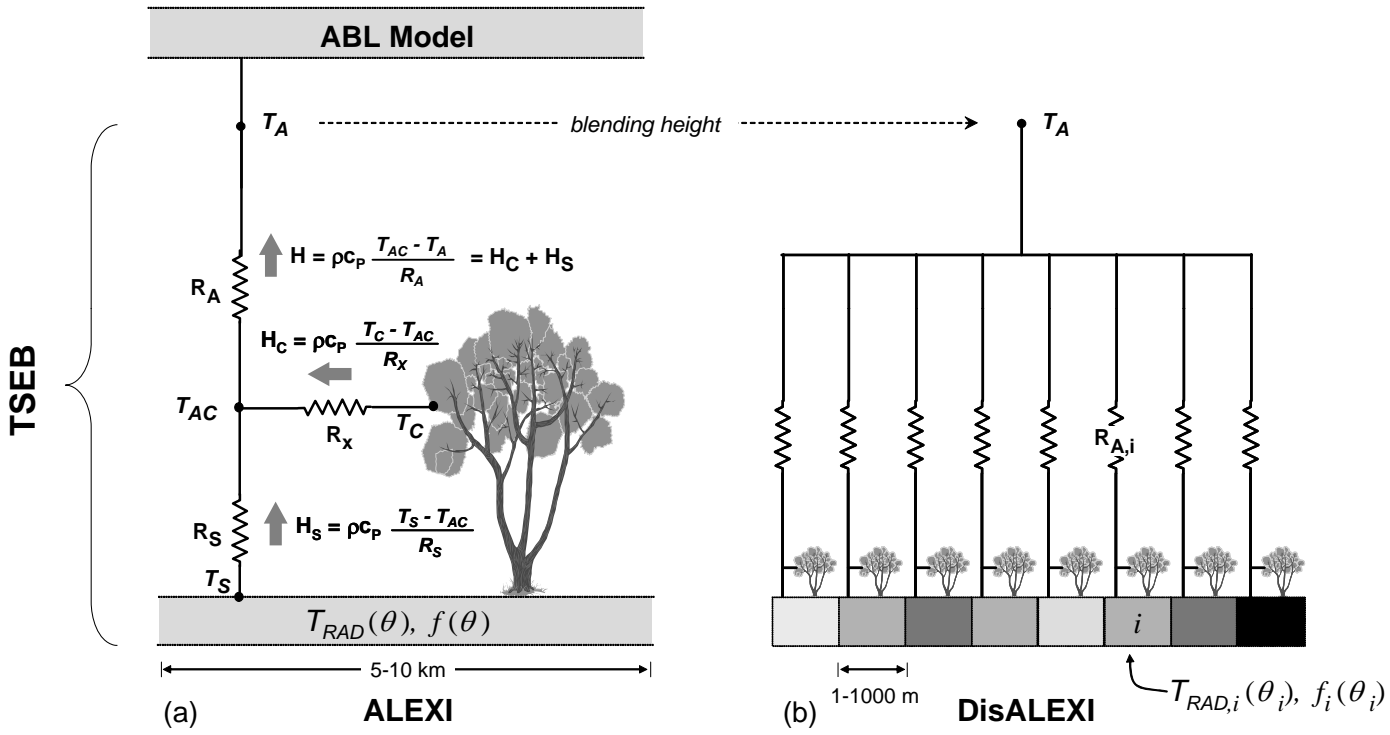

Fig. 1. Schematic diagram representing the ALEXI (a) and DisALEXI (b) modeling schemes, highlighting fluxes of sensible heat $(H)$ from the soil and canopy (subscripts "s" and "c") along gradients in temperature ( $T$ ), and regulated by transport resistances $R_{\mathrm{A}}$ (aerodynamic), $R_{X}$ (bulk leaf boundary layer) and $R_{\mathrm{S}}$ (soil surface boundary layer). DisALEXI uses the air temperature predicted by ALEXI near the blending height $\left(T_{\mathrm{A}}\right)$ to disaggregate 10-km ALEXI fluxes, given vegetation cover $(f(\theta))$ and directional surface radiometric temperature $\left(T_{\mathrm{RAD}}(\theta)\right)$ information derived from high-resolution remote-sensing imagery at look angle $\theta$.

The land-surface representation in ALEXI model is based on the series version of the two-source energy balance (TSEB) model of Norman et al. (1995; see also Kustas and Norman, 1999, 2000), which partitions the composite surface radiometric temperature, $T_{\mathrm{RAD}}$, into characteristic soil and canopy temperatures, $T_{\mathrm{S}}$ and $T_{\mathrm{C}}$, given the local vegetation cover fraction apparent at the thermal sensor view angle, $f(\theta)$ :

$T_{\mathrm{RAD}}(\theta)=\left[f(\theta) T c^{4}+[1-f(\theta)] T s^{4}\right]^{1 / 4}$

(Fig. 1). For a homogeneous canopy with spherical leaf angle distribution and leaf area index LAI, $f(\theta)$ can be approximated as

$f(\theta)=1-\exp \left(\frac{-0.5 \Omega(\theta) \mathrm{LAI}}{\cos \theta}\right)$

where $\Omega(\theta)$ is a view angle dependent clumping factor, currently assigned by vegetation class (Anderson et al., 2005). With information about $T_{\mathrm{RAD}}$, LAI, and radiative forcing, the TSEB evaluates the soil (subscript "s") and the canopy ("c") energy budgets separately, computing system and component fluxes of net radiation $\left(\mathrm{RN}=\mathrm{RN}_{\mathrm{C}}+\mathrm{RN}_{\mathrm{S}}\right)$, sensible and latent heat $\left(H=H_{\mathrm{C}}+H_{\mathrm{S}}\right.$ and $\left.\lambda E=\lambda E_{\mathrm{C}}+\lambda E_{\mathrm{S}}\right)$, and soil heat conduction $(G)$. Importantly, because angular effects are incorporated into the decomposition of $T_{\mathrm{RAD}}$, the TSEB can accommodate thermal data acquired at off-nadir viewing angles and can therefore be applied to geostationary satellite images.

The TSEB has a built-in mechanism for detecting thermal signatures of vegetation stress. A modified Priestley-Taylor relationship (PT; Priestley and Taylor, 1972) applied to the divergence of net radiation within the canopy $\left(\mathrm{RN}_{\mathrm{C}}\right)$, provides an initial estimate of canopy transpiration $\left(\lambda E_{\mathrm{C}}\right)$, while the soil evaporation rate $\left(\lambda E_{\mathrm{S}}\right)$ is computed as a residual to the system energy budget. If the vegetation is stressed and transpiring at significantly less than the potential rate, the PT equation will overestimate $\lambda E_{\mathrm{C}}$ and the residual $\lambda E_{\mathrm{S}}$ will become negative. Condensation onto the soil is unlikely to occur midday on clear days, and therefore $\lambda E_{\mathrm{S}}<0$ is considered a signature of system stress. Under such circumstances, the PT coefficient is throttled back until $\lambda E_{\mathrm{S}} \sim 0$ (expected under dry conditions). Both $\lambda E_{\mathrm{C}}$ and $\lambda E_{\mathrm{S}}$ will then be some fraction of the potential ET rates associated with the canopy and soil. This approach therefore opens the potential for surface (related to $\lambda E_{\mathrm{S}}$ ) and root zone (related to $\lambda E_{\mathrm{C}}$ ) moisture pool assessment, and thus concomitant tracking of both meteorological and agricultural drought (Kustas and Anderson, 2009). Alternatively, a light-use efficiency based version of the TSEB estimates coupled transpiration and carbon assimilation fluxes using an analytical expression for canopy conductance (Anderson et al., 2008).

Regional-scale applications of the TSEB require specification of the near-surface air-temperature boundary condition across the domain $\left(T_{\mathrm{A}}\right.$ in Fig. 1), which is difficult to accomplish with adequate accuracy over large areas. Because near-surface atmospheric properties can be strongly coupled to local surface conditions, interpolation between synoptic weather network observations of $T_{\mathrm{A}}$ can result in large errors in the assumed surface-to-air temperature gradient $\left(T_{\mathrm{RAD}}-T_{\mathrm{A}}\right)$ driving the modeled sensible heat flux. 
Therefore, for regional applications the TSEB has been coupled with an atmospheric boundary layer (ABL) model to internally simulate land-atmosphere feedback on $T_{\mathrm{A}}$. In the ALEXI model, the TSEB is applied at two times during the morning ABL growth phase (1 to $1.5 \mathrm{~h}$ after sunrise and before local noon), using radiometric temperature data obtained from a geostationary platform like GOES at spatial resolutions of $\sim 5-10 \mathrm{~km}$. Energy closure over this interval is provided by a simple slab model of ABL development (McNaughton and Spriggs, 1986), which relates the rise in air temperature in the mixed layer to the time-integrated influx of sensible heat from the land surface. As a result of this configuration, ALEXI uses only time-differential temperature signals, thereby minimizing flux errors due to absolute sensor calibration and atmospheric and spatial effects (Kustas et al., 2001). The primary radiometric signal is the morning surface temperature rise, while the ABL model component uses only the general slope (lapse rate) of the atmospheric temperature profile (Anderson et al., 1997), which is more reliably analyzed from synoptic radiosonde data than is the absolute temperature reference.

A complete ALEXI processing infrastructure has been developed to automatically ingest and pre-process all required input data, to execute the model, and to post-process model output for visual display and use in other applications. Because TIR retrievals of LST are possible only under clear-sky conditions, a gap-filling algorithm has been implemented to estimate ET during cloudy intervals (Anderson et al., 2007c). Running moisture pools are maintained across the model grid for the surface and root-zone soil layers, and are updated each clear day assuming a functional relationship between available water fraction and the actual-to-potential ET ratio computed by ALEXI for the soil and canopy components, respectively. On cloudy days, these relationships are inverted to predict $\lambda E_{\mathrm{S}}$ and $\lambda E_{\mathrm{C}}$ based on the current day's modelled soil moisture status.

The gap-filled model currently runs daily on a $10-\mathrm{km}$ resolution grid covering the continental US (CONUS) using data from the Geostationary Operational Environmental Satellites (GOES). Primary ALEXI model inputs are summarized in Table 2, along with data sources used for CONUS implementation. To date model input/output from this framework have been archived for the period 2000-present, limited currently by the extent of the MODIS dataset used to supply LAI model inputs. In the future, the CONUS archive can be extended back to 1979 using GOES imagery archive at National Climatic Data Center (NCDC) through the International Satellite Cloud Climatology Project (ISCCP) B1 Data Rescue project (Knapp, 2008) and long-term multisensor LAI data records (e.g., Ganguly et al., 2008). In addition, new domains have recently been initiated over Europe and Africa using Meteosat Second Generation (MSG) land-surface products generated and distributed by the Land Surface Analysis Satellite Applications Facility (LSA SAF; Trigo et al., 2010), with other data sources listed in Table 2.

\subsubsection{DisALEXI}

ALEXI is constrained to operate on spatial scales of 5$10 \mathrm{~km}$, where atmospheric forcing by uniform land-surface behavior becomes effective. Anderson et al. (2007a) summarize ALEXI validation experiments employing a spatial flux disaggregation technique (DisALEXI; Norman et al., 2003), which uses uses air temperature diagnoses from ALEXI along with higher resolution TIR imagery presently only available from aircraft or polar orbiting systems such as Landsat, ASTER, or MODIS to downscale the GOES-based flux estimates $(10 \mathrm{~km}$ resolution) to the flux measurement footprint scale (on the order of 100-1000 m; see Fig. 1). Typical root-mean-square-deviations in comparison with tower flux measurements (30-min averages) of $H$ and $\lambda E$ are 35$40 \mathrm{~W} \mathrm{~m}^{-2}$ (15\% of the mean observed flux) over a range in vegetation cover types and climatic conditions. Disaggregation also facilitates high spatial resolution assessment of moisture flux and stress conditions, but is constrained in temporal resolution by the overpass frequency of the polar orbiting satellite. Together, ALEXI/DisALEXI facilitate scalable flux and moisture stress mapping using thermal imagery from a combination of geostationary and polar orbiting satellites, zooming in from the national scale to sites of specific interest (Fig. 2).

\subsection{Thermal sharpening}

For instrumental reasons, TIR imagers typically operate at coarser spatial resolution than do visible (vis) and nearinfrared (NIR) band sensors on the same satellite platform. For example, to complement the thermal imaging described in Table 1, MODIS collects vis/NIR data at $250 \mathrm{~m}$, while Landsat and ASTER have shortwave band instruments at 30$\mathrm{m}$ and $10-\mathrm{m}$ resolution, respectively. These higher resolutions are more beneficial for many types of hydrologic applications, particularly over highly fragmented agricultural landscapes. Fortunately, a strong inverse relationship typically exists between land-surface temperature and vegetation indices (VIs) derived from vis/NIR data (e.g., Goward et al., 1985; Hope and McDowell, 1992; Smith and Choudhury, 1991), which can be exploited to improve the spatial resolution of TIR band imagery over many scenes to that of associated vis/NIR band instruments. This relationship reflects the fact that denser vegetation cover tends to be correlated with lower surface temperatures, due to cooling by transpiration.

Kustas et al. (2003) presented a simple generalized TIR image sharpening algorithm based on this concept. First the VI image is spatially aggregated to the TIR resolution, then a subset of relatively homogeneous coarse-scale pixels are selected and a functional fit is developed between TIR and VI at this coarser resolution. This function is then applied to the VI data at their higher native resolution to determine a first guess at the high-resolution LST map. The final step applies a bias correction, so that the original TIR image is 
Table 2. Primary inputs required by ALEXI, data sources used over the CONUS, Europe/Africa domains, and proposed sources for a global application.

\begin{tabular}{llllll}
\hline Data & Purpose & CONUS & $\begin{array}{l}\text { Europe } \\
\text { Africa }\end{array}$ & Global & $\begin{array}{l}\text { Temporal } \\
\text { resolution }\end{array}$ \\
\hline LST & $\Delta T_{\text {RAD }}$, RN & GOES (GSIP) & MSG & Geoland2 $^{\mathrm{e}}$ & hourly \\
Insolation & RN & GOES (GSIP) & MSG & Geoland2 & hourly \\
Longwave rad & RN & GOES (GSIP) & MSG & Geoland2 & hourly \\
Wind speed & Aerodynamic resistances & NARR $^{\mathrm{b}}$ & WRF $^{\mathrm{d}}$ & MERRA $^{\mathrm{f}}$ & $3 \mathrm{~h}$ \\
Lapse rate profile & ABL growth model & NARR & WRF & MERRA & $3 \mathrm{~h}$ \\
LAI & $T_{\text {RAD partitioning }}$ & MODIS & MODIS & MODIS & 8 -day \\
Landcover type & Surface characteristics & UMD global & UMD global & UMD global fixed \\
\hline
\end{tabular}

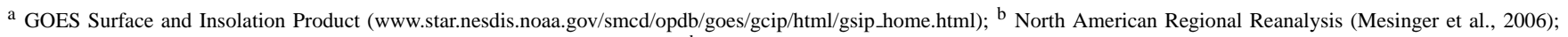
${ }^{\mathrm{c}}$ University of Maryland global landcover classification (Hansen et al., 2000); ${ }^{\mathrm{d}}$ Weather Research and Forecasting model (Skamarock et al., 2005); ${ }^{\mathrm{e}}$ GMES global land monitoring database (Lacaze et al., 2010); ${ }^{\mathrm{f}}$ GMAO Modern Era Retrospective Analysis for Research and Applications (Bosilovich et al., 2008)

recovered when aggregated to the TIR resolution. The bias is defined as a residual field computed by aggregating the predicted TIR image, then subtracting from the original TIR image.

Anderson et al. (2004) investigated the impact of thermal sharpening on DisALEXI flux maps over agricultural landscapes in Oklahoma, derived from Landsat TIR imagery sharpened to $30-\mathrm{m}$ resolution. The sharpening procedure successfully enhanced fine spatial details such as field borders, residential streets, and golf-course fairways. It was determined that better results were obtained if residual fields are smoothed via convolution before reintroduction into the predicted temperature maps. The residual maps themselves were found to contain interesting information about soil moisture variability, a second principle driver of surface temperature variations along with vegetation amount. The NDVI-based sharpening methods described by Kustas et al. (2003) have been further improved by Merlin et al. (2010) to account for impacts of non-green vegetation (e.g., stubble or residue) on surface temperature variations.

Agam et al. (2007a, b, 2008) further tested the sharpening procedure over a rainfed agricultural landscape in Iowa and an irrigated region in Texas, and discovered limitations to the resolution range over which sharpening can be successfully applied. In short, temperature variations due to subpixel moisture variability cannot be recovered unless they are well-correlated with vegetation features. Therefore dominant moisture variations must be well-resolved at the native TIR resolution. This is further demonstrated in Fig. 3, showing a simulated sharpening exercise over an irrigated area in Texas. A half-pivot region in the northeast quadrant has been given a shot of irrigation pre-emergence to stimulate seedling growth. Because this moisture signal has no detectable VI counterpart (the plants have not yet emerged), it disappears in sharpening from the MODIS 1-km scale to $30 \mathrm{~m}$ because it was not well-resolved by the MODIS TIR imagery. Indeed, the fundamental TIR-VI relationship derived in this exam- ple appears to be faulty, resulting in an over-enhancement in temperature contrast across the sharpened image.

These results suggest that while thermal sharpening is a valuable tool for enhancing spatial information content in TIR imagery, it does not replace the need for TIR data collection at the sub-field scale as currently provided by Landsat. However, Landsat and ASTER TIR imagery can be effectively improved through sharpening even over irrigated landscapes because the moisture variability is largely resolved at the native Landsat resolution.

\subsection{Data fusion}

While MODIS data cannot supplant the need for Landsatscale TIR imagery, they can be effectively used to inform temporal interpolation of high resolution ET fields. The standard technique currently used to generate daily, monthly and seasonal ET estimates at the 30-m scale, as needed for many agriculture water management applications, is to directly interpolate between infrequent Landsat-derived ET images, perhaps conserving some quantity such as the ratio of actualto-reference ET during the intervening gap to capture evaporative response to temporal variability in radiation load and atmospheric demand (e.g., Allen et al., 2007). In perpetually cloudy regions, however, we may obtain only two or three clear Landsat TIR images per growing season, providing insufficient temporal sampling to reliably assess daily and cumulative water consumption.

Using new data fusion techniques, such as the Spatial Temporal Adaptive Reflectance Fusion Model (STARFM) developed by Gao et al. (2006), we can improve seasonal high-resolution ET estimates by integrating daily information at moderate resolution from wide-swath sensors like MODIS with periodic high-resolution maps from Landsat. The STARFM approach was first developed to blend surface reflectance between high spatial resolution Landsat and high temporal resolution MODIS data. The approach uses 


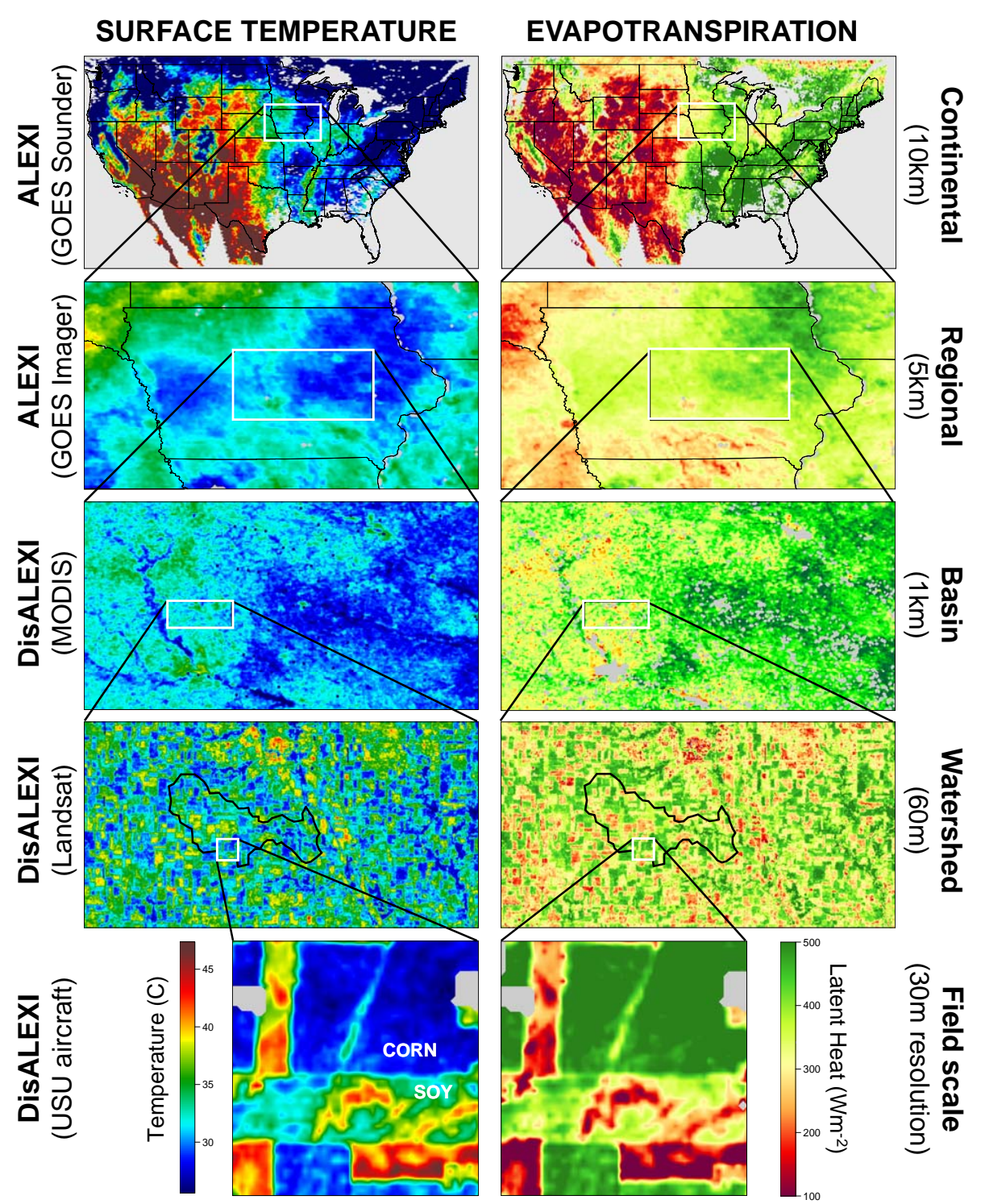

1 July $2002-10: 30$ AM CST

Fig. 2. Multi-scale ET maps for 1 July 2002 produced with ALEXI/DisALEXI using surface temperature data from aircraft (30-m resolution), Landsat (60-m), MODIS (1-km), GOES Imager (5-km) and GOES Sounder (10-km), zooming into the Walnut Creek Watershed near Ames, Iowa, site of the SMEX02 Soil Moisture Experiment. The continental-scale ET map is a 14-day composite of clear-sky model estimates (figure from Anderson and Kustas, 2008).

spectrally similar pixels in Landsat images and temporal changes determined from MODIS. STARFM predicts Landsat resolution reflectance at the MODIS acquisition date based on the temporal change from MODIS and a deterministic weighting function determined by spectral similarity, temporal difference, and spatial distance.

Figure 4 shows an example of ET data fusion over the Orlando region of southern Florida, an area where water-use monitoring is critical due to a convergence of high population density and agricultural development adjacent to the sensitive wetland areas of the Florida Everglades. In this ex- ample, ALEXI is used to map daily ET at 10-km resolution over CONUS, gap-filling cloudy pixels using the algorithm described by Anderson et al. (2007c). Gap-filled maps at $1-\mathrm{km}$ resolution over the state of Florida were generated using DisALEXI applied to the daily MODIS swath LST product (MOD11-L2). Disaggregation was also applied to clear Landsat TIR scenes acquired during this period, in this case available 8 days apart from the Landsat 5 and 7 satellites on day of year (DOY) 328 and 336. Both Landsat TIR scenes were sharpened to $30-\mathrm{m}$ resolution using the techniques described in Sect. 2.2. 


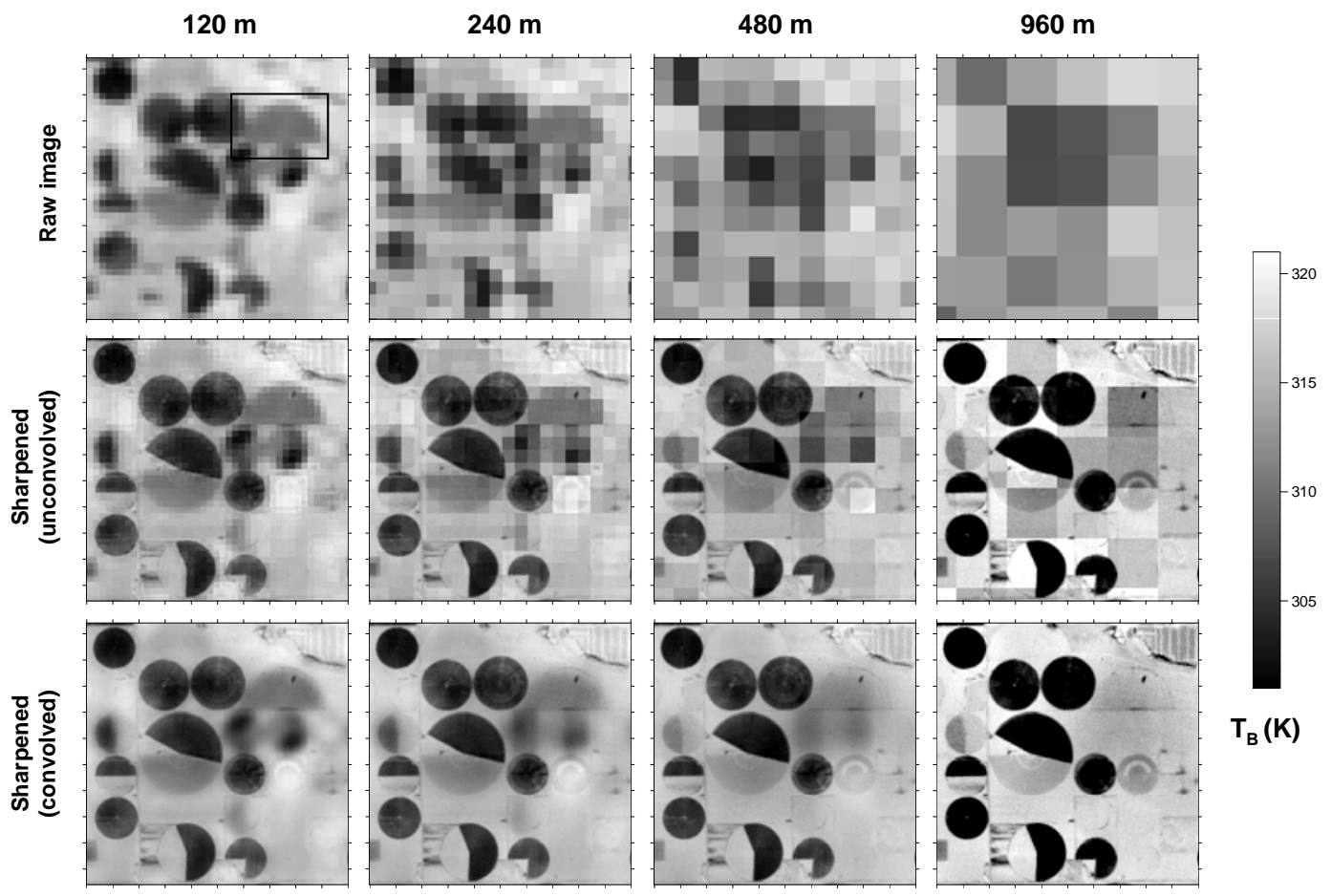

Fig. 3. Example of thermal sharpening applied to data aggregated from a Landsat 5 scene over an irrigated agricultural area in the Texas Panhandle. Top row shows TIR imagery at 120-m native resolution (left column) and aggregated to $240 \mathrm{~m}, 480 \mathrm{~m}$, and $960 \mathrm{~m}$ (right column), the latter approximating MODIS TIR resolution. These fields were sharpened to $30 \mathrm{~m}$ resolution using Landsat-derived NDVI, using unconvolved (middle row) and convolved (bottom row) residual fields. The box in the 120 -m raw image (upper left) highlights a recently irrigated area with low vegetation cover, which disappears in the 960-m sharpened image (lower right), demonstrating limitations in the capabilities of the sharpening algorithm.

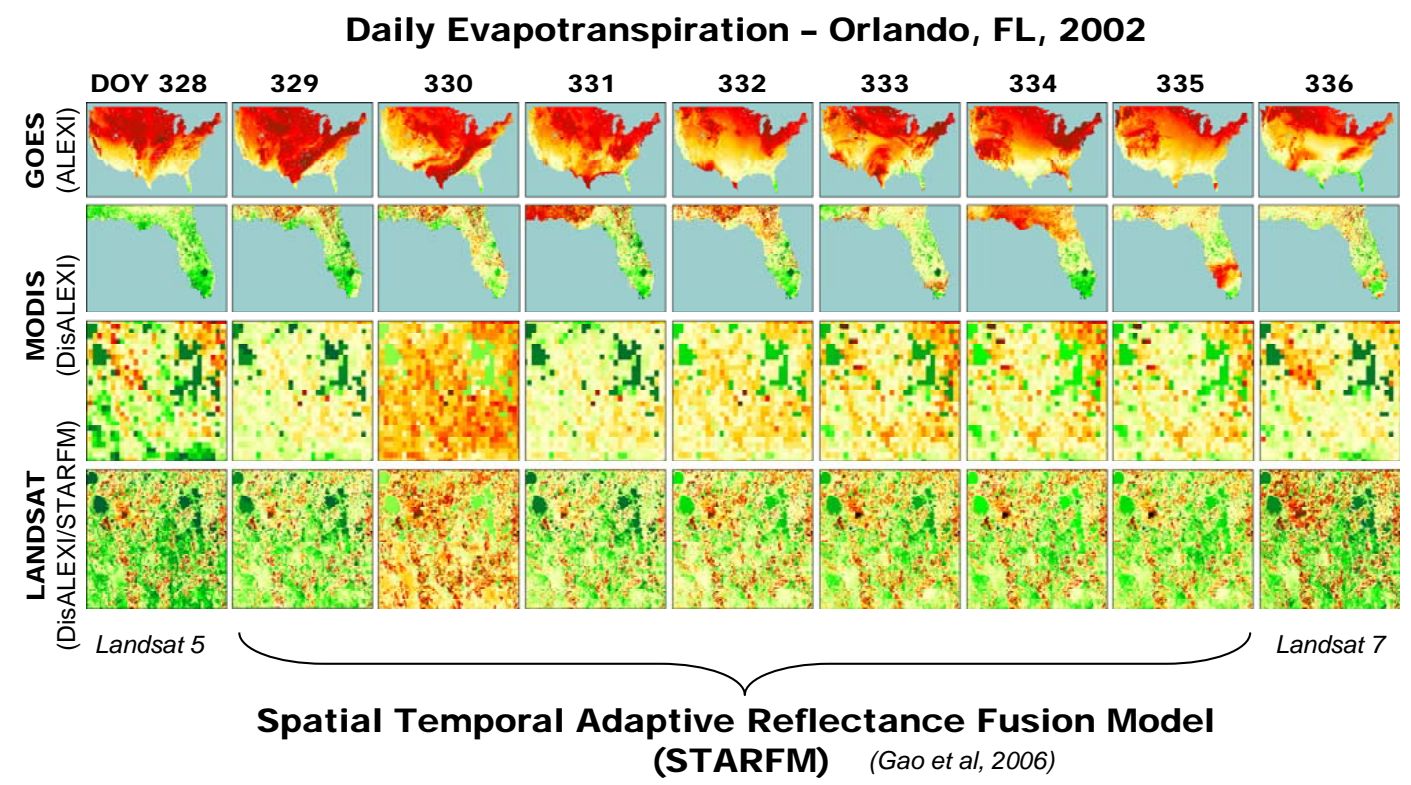

Fig. 4. Example of Landsat/MODIS/GOES ET data fusion, showing maps of daily ET from ALEXI at 10-km resolution (top row), at from DisALEXI using MODIS TIR at 1-km resolution (middle rows), and from the STARFM data fusion algorithm, fusing information from DisALEXI using Landsat TIR sharpened to 30-m resolution (bottom row). 

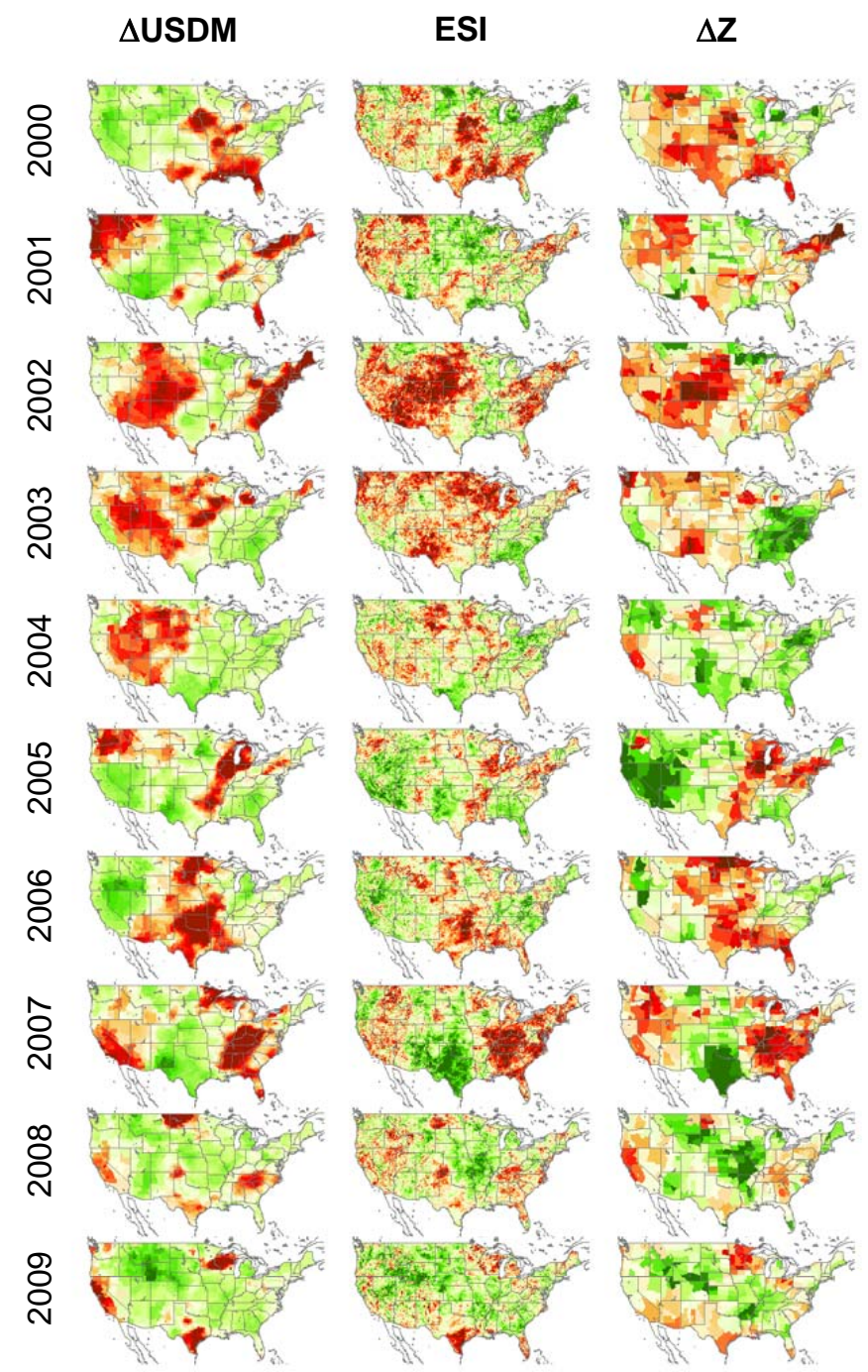

$\Delta$ SPI-6
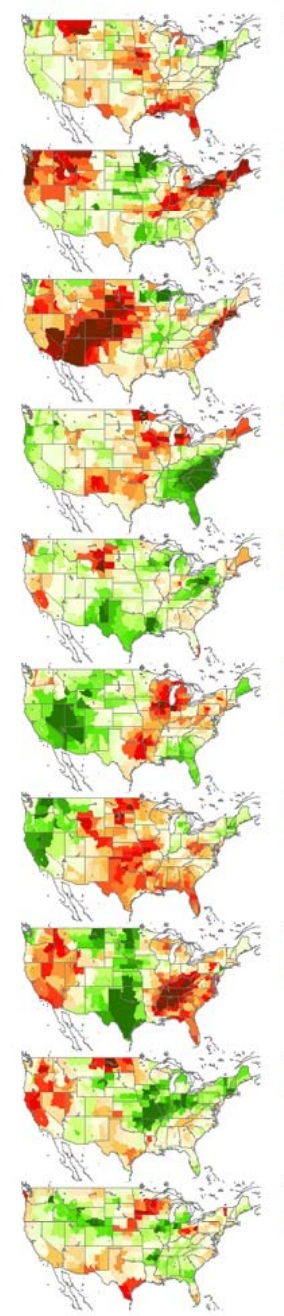

Wetter $\triangle$ PDSI
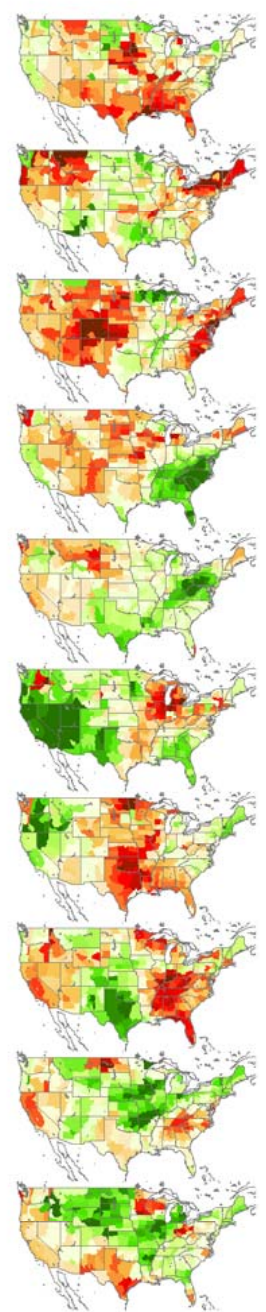

\section{Drier}

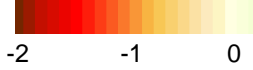

1

Fig. 5. Seasonal (26-week) anomalies in the USDM, ESI, Z, SPI-6, and PDSI for 2000-2009.

Finally, information from the MODIS-Landsat ET image pairs on DOY 328 and 336 are fused using STARFM, generating disaggregation statistic maps that are applied to daily MODIS fields for DOY 329-335, thus forming a continuous time series at 30-m resolution. Comparisons between predicted (STARFM) and observed (DisALEXI) Landsatscale ET fields yield errors on the order of $10 \%$. Although STARFM was originally designed to fuse shortwave reflectance fields, it appears to hold great utility for highresolution ET mapping as well. Further studies are underway to quantify prediction accuracy over seasonal timescales.

\section{Applications}

Section 2 described techniques for generating daily remote sensing fields of ET at resolutions of $10 \mathrm{~m}$ to $10 \mathrm{~km}$, covering areas from watershed to continental scales. Here we describe examples of how diagnostic ET information at multiple scales are being applied for purposes of drought monitoring, agricultural water resource management, and hydrologic decision support in major river basins. These examples demonstrate recent ALEXI applications using GOES geostationary data over CONUS, and MSG land-surface products over Europe and Africa. 


\subsection{United States: drought monitoring}

Spatial and temporal variations in instantaneous ET at the continental scale are primarily due to variability in moisture availability (antecedent precipitation), radiative forcing (cloud cover, sun angle), vegetation amount, and local atmospheric conditions such as air temperature, wind speed and vapor pressure deficit. Potential ET describes the evaporation rate expected when soil moisture is non-limiting, ideally capturing response to all other forcing variables. To isolate effects due to spatially varying soil moisture availability, a simple Evaporative Stress Index (ESI) can be developed from the departure of model flux estimates of ET from the potential rate (PET) expected under non-moisture limiting conditions. The ESI reflects temporal anomalies in the ET/PET ratio, and shows good correspondence with standard drought metrics and with patterns of antecedent precipitation, but at significantly higher spatial resolution due to limited reliance on ground observations (Anderson et al., 2007b). This ratio has a value of 1 when there is ample moisture/no stress, and a value of 0 when ET has been cut off due to stress-induced stomatal closure and/or complete drying of the soil surface. It therefore serves as a valuable proxy indicator for available soil moisture (Hain, 2010; Hain et al., 2009). Where there is vegetation, the proxy reflects information over the full rootzone, while it reflects surface moisture conditions (top $5 \mathrm{~cm}$ of soil profile) in areas of very sparse vegetation.

Annual standardized anomalies in several drought indicators are compared in Fig. 5, computed from 26-week composites (April-September) over the 2000-2009 growing seasons for CONUS (Anderson et al., 2011). The metrics displayed include anomalies in US Drought Monitor (USDM) drought classifications (Svoboda et al., 2002), the ESI, and three precipitation-based drought indices (the Palmer Z Index, Z; the 6-month Standardized Precipitation Index, SPI-6; and the Palmer Drought Severity Index, PDSI), which were selected to exemplify a range in timescales and modeling approaches. These figures demonstrate the responsiveness of the various indices to changing moisture conditions, and the degree to which salient moisture features are emphasized or missed in each index.

Drought features recorded in the USDM are generally reflected in one or more of the other indices, but to varying degrees depending on drought type and timescale. The hydrologic drought in the western US in 2004 reflects a long-term moisture deficit accumulated from 2002, for example, is not delineated in the 26-week drought index composites shown here. In other years, the ESI successfully reproduces patterns evident in the precipitation indices, indicating the value of the LST signal as a surface moisture proxy. For example, the thermal band inputs to ALEXI capture the major drought events occurring in 2002 and 2007, even in the eastern US where there is dense vegetation cover mid-season, and little exposure of the dry soil surface.
Figure 6 looks in greater detail at the drought of 2007 that ravaged much of the southeastern US (particularly in Alabama, Georgia, and the Carolinas), leading to low stream flows, depleted water supplies, and significant agricultural losses. This is a part of CONUS where standard soil moisture retrievals based on passive microwave remote sensing tend to lose sensitivity due to strong attenuation of the soil signal by water contained in the dense forest canopy, as demonstrated in Fig. 6c. In the thermal band, however, the moisture deficit signal is strong - vegetation stress and soil moisture depletion in the surface skin contribute to elevated canopy and soil components of the composite surface radiometric temperature. The ESI reproduces patterns in soil moisture predicted by the Noah land-surface model (part of the Land Data Assimilation System (LDAS) modeling suite; Mitchell et al., 2004), with the advantage of requiring no antecedent precipitation information.

Incorporating the thermal sharpening and data fusion techniques described in Sect. 2, we can generate daily time series required to compute ESI anomalies over targeted areas at up to $10-\mathrm{m}$ resolution. This will facilitate drought and crop condition assessments at sub-county to field scales, which will be valuable for yield forecasting and distribution of droughtinduced yield loss compensation. Reliable precipitation data at these spatial scales are particularly difficult to obtain, underscoring the value of this kind of diagnostic TIR-based monitoring technique.

\subsection{Europe: irrigation management}

A variety of remote sensing techniques have been used to study the surface energy balance and evapotranspiration over the European continent, and in particular in the Mediterranean regions where irrigation demands on water resources are high (e.g., Rana and Katerji, 2000; Detto et al., 2006; Sánchez et al., 2008; Sobrino et al., 2009; Minacapilli et al., 2009; van der Kwast, 2009). Scalable, spatially distributed estimates of water use derived from multiple satellite platforms can help to link water distribution decision making at the irrigation district scale to overall climatic moisture conditions at the continental scale.

Using land-surface temperature, insolation, and leaf area index products developed from MSG imagery by the LSA SAF (Trigo et al., 2011), an ALEXI model domain has recently been established over much of Europe. Figure 7 shows monthly clear-sky composites of latent heat flux (near solar noon) at $10-\mathrm{km}$ resolution over the European domain for 2008. Cut-offs in the northern part of domain through June reflect view angle limitations in the land-surface temperature product through that date.

Validation experiments are underway in Spain and Italy, using disaggregation to compare model fluxes to tower observations, and to study agricultural water use in varying climatic regimes and cropping systems. 

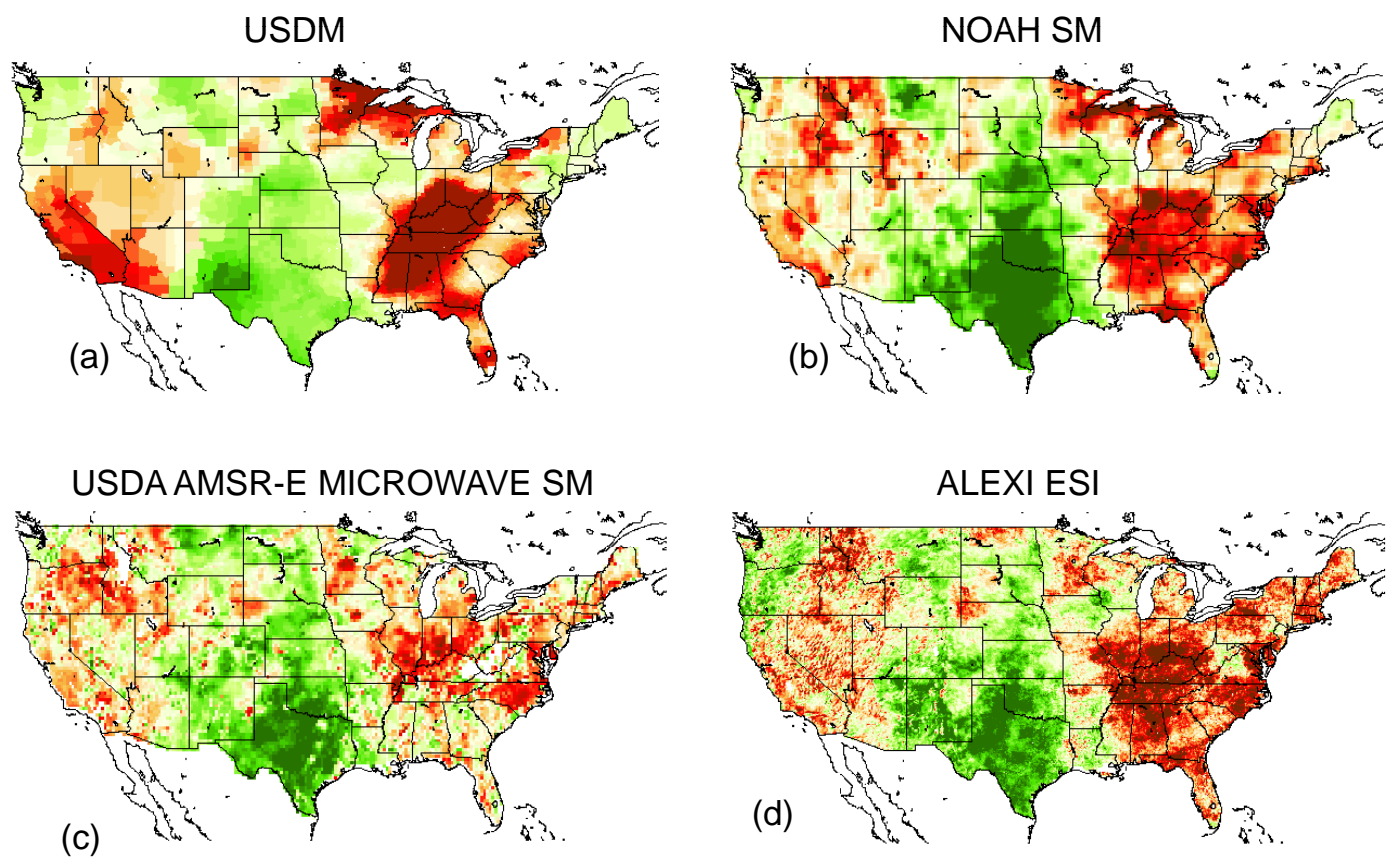

Drier
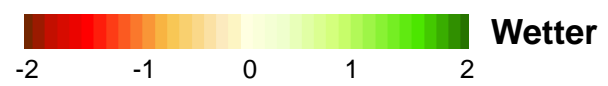

Fig. 6. Anomalies for the 2007 growing season (April-September) in (a) the USDM drought classes, (b) soil moisture predicted by the LISNoah land-surface model, (c) USDA AMSR-E (Advanced Microwave Scanning Radiometer - Earth Observing System) passive microwave soil moisture retrieval and (d) ALEXI ESI.

\subsubsection{Spain}

Competition for scarce water resources in Southern Spain, as well as the entire Mediterranean Sea Basin, is now in evidence. Future water shortages are likely to be worsened by the increasing demand produced by demographic growth, the expanding tourist industry, and the decrease in fresh water supply predicted under conditions of climate change, which is expected to make this region both warmer and drier.

The Guadalquivir River Basin is the largest $\left(57527 \mathrm{~km}^{2}\right)$ in Southern Spain, and supports extensive agricultural production (around $8000 \mathrm{~km}^{2}$ of irrigated land). Irrigated areas in this basin are responsible for $60 \%$ of total agricultural production in the basin, consuming around $86 \%$ of its total water resources (CHG, 2008). Despite its large capacity, the basin suffers systematic water deficits and new storage cannot be developed. The only opportunity to reach a sustainable use of water is the improvement of water management, which requires timely and accurate information about the water use by the different crops and irrigation districts. Accurate determination of water balance components, especially ET, is difficult given the complex landscape and typically small field sizes.

To this end, an effort led by the River Basin Authority is under way to estimate the use of water in irrigated ar- eas, initially by using a water balance approach combined with remotely sensed vegetation indices (Díaz et al., 2009; González-Dugo and Mateos, 2008). More recently, the ALEXI/DisALEXI system has been applied in this region, introducing additional information about surface moisture condition conveyed by remotely sensed land-surface temperature. Figure 8 shows a time sequence of ALEXI and DisALEXI maps of ET, zooming in from a domain covering Spain to an irrigated agricultural area along the Guadalquivir River in southern Spain. The DisALEXI maps were generated with Landsat 5 and 7 TIR imagery sharpened to $30 \mathrm{~m}$ resolution, and show a steady decline in local moisture conditions as the season progresses. The typical size of these fields $(200 \mathrm{~m})$ motivates the need for high-resolution ET maps - the 1 to $3-\mathrm{km}$ resolution of the MODIS/MSG TIR sensors cannot resolve the irrigated fields and will underestimate evaporative losses along this patchy irrigated agricultural system. An evaluation of daily 30-m ET estimates generated over this two-month time span, generated through fusion of MSG, MODIS and Landsat-derived ET as described in Sect. 2.3, is underway in comparison with flux measurements collected at an eddy correlation tower deployed in a corn field near the center of the Landsat maps in Fig. 8. If reliable, daily remote sensing products can provide water managers with accurate information at field, irrigation district, and basin scales about 

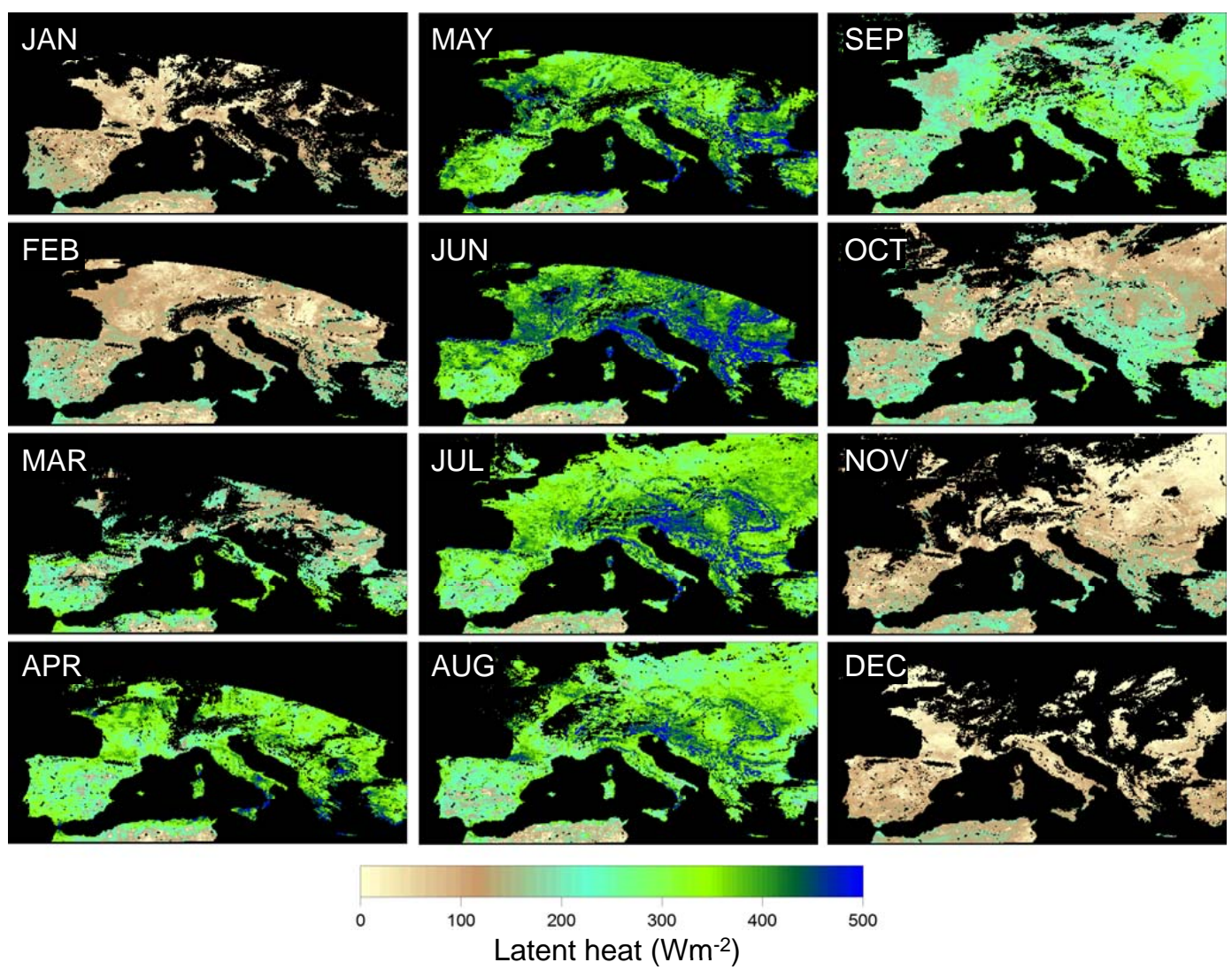

Fig. 7. Monthly composites of clear-sky latent heat flux (instantaneous, shortly before local noon) for 2008 over Europe, generated at 10-km resolution by ALEXI using MSG land-surface products. Snow-covered regions have not been simulated.

\section{June 20}
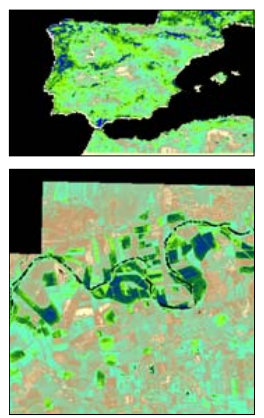

July 6
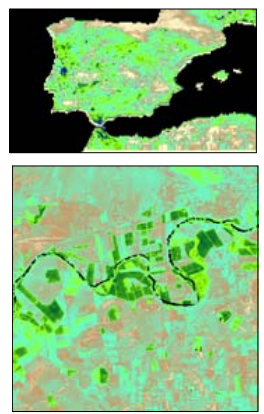

July 22
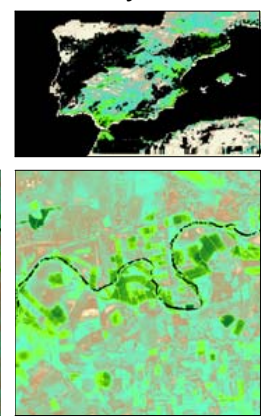

Aug 7
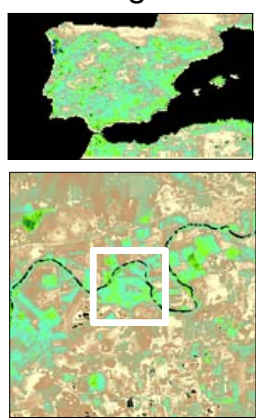

Aug 23

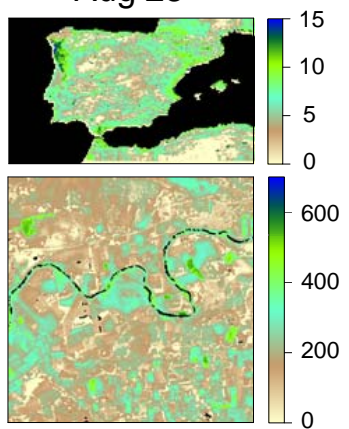

Fig. 8. Maps of daytime ET ( $\mathrm{MJ} \mathrm{m}^{-2} \mathrm{~d}^{-1}$ ) from ALEXI over Spain (top row) and instantaneous ET (shortly before local noon; $\mathrm{W} \mathrm{m}^{-2}$ ) from DisALEXI over an irrigated agricultural area along the Guadalquivir River in southern Spain (bottom row) for five days during the 2009 growing season. White box on the Aug 7 DisALEXI map indicates the 3-km MSG pixel size.

spatial and temporal patterns of water used by various crop types to make better decisions concerning water distribution.

\subsubsection{Italy}

The challenge of irrigation management in the Mediterranean area of Italy can also be advanced using remotesensing based estimations of evapotranspiration fluxes at both plot and district scales (D'Urso, 2001; Minacapilli et al., 2008, 2009). The main complexity of this region is the extreme landscape spatial fragmentation, with a mean field size of few hectares, which requires adequate high resolution $\left(10^{0}-10^{1} \mathrm{~m}\right)$ retrieval of ET maps. An additional degree of complexity is due to the sparse configuration of typical Mediterranean crops (olive trees, grapes, citrus), where 


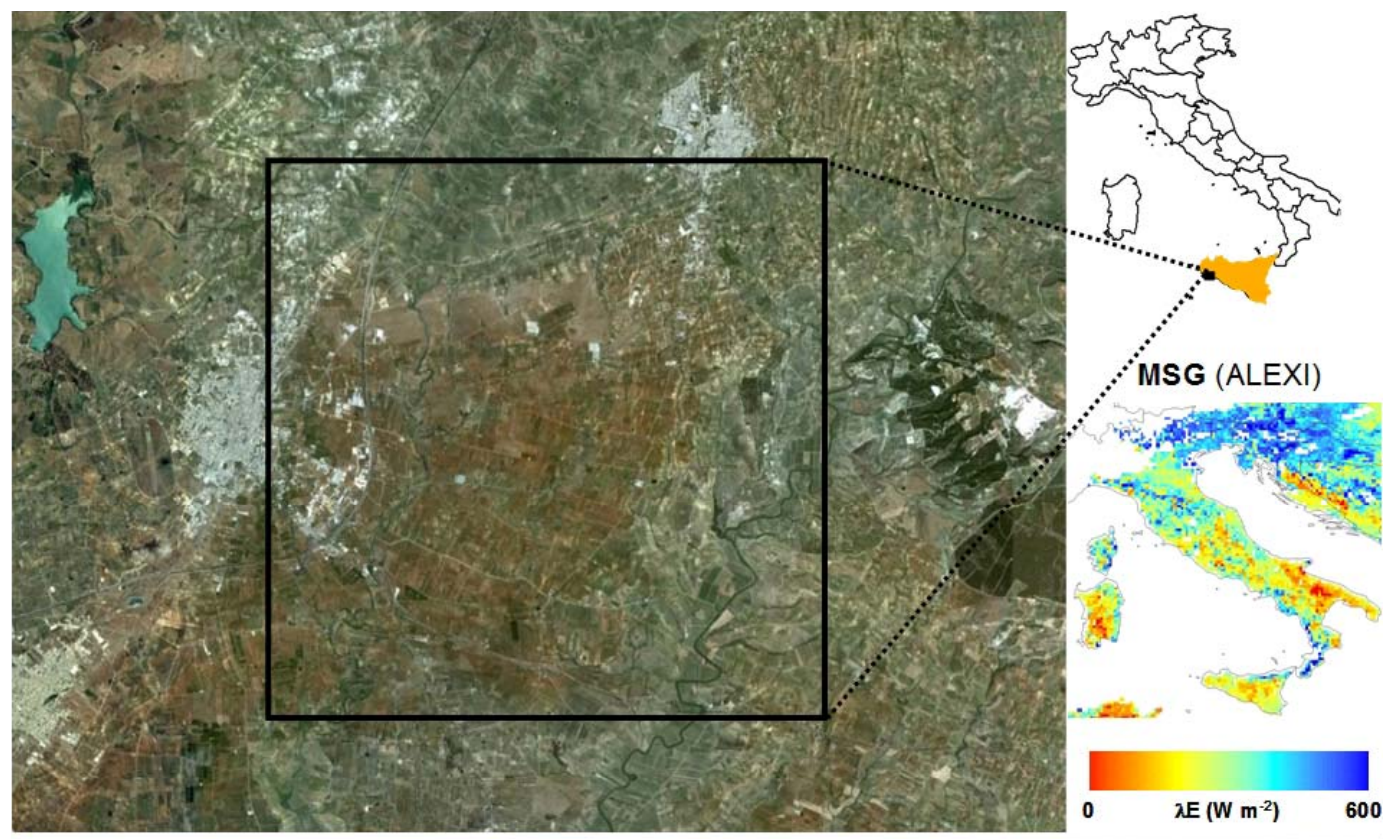

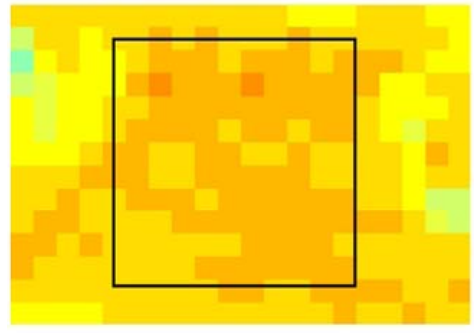

MODIS (DisALEXI)

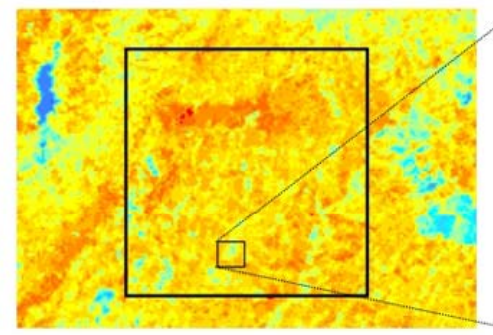

Landsat (DisALEXI)

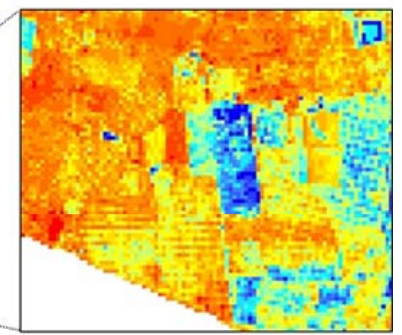

Airborne (DisALEXI)

Fig. 9. Multi-scale clear-sky latent heat flux maps (shortly before noon) produced for 22 July 2008 with ALEXI/DisALEXI using surface temperature data from MSG (10-km), MODIS (1-km), Landsat (60-m) and aircraft (10-m resolution). Black boxes on the orthophoto (top), MODIS and Landsat images highlight an MSG pixel size, while the airborne image shows the Castelvetrano (Sicily) experimental site in the Belice Watershed.

a significant fraction of exposed bare soil necessitates a detailed partitioning of latent heat fluxes in its main components (transpiration and evaporation) to get at actual crop water consumption.

In this context, the multi-resolution capabilities of ALEXI/DisALEXI, coupled with the two-source partitioning facilitated by the embedded TSEB land-surface representation, provides a useful framework for addressing the major challenges of Mediterranean agriculture. This modeling system also significantly reduces errors caused by uncertainty in surface-air temperature differences, to which most residual energy balance approaches are highly sensitive (Choi et al., 2009; Norman et al., 2000).

Typical results of ALEXI/DisALEXI application are reported in Fig. 9 for a test site near Castelvetrano, on the southwest coast of Sicily (Italy), dominated by olive groves. The $\lambda E$ maps in this figure highlight how the landscape-scale patterns are well reproduced using Landsat thermal data, and to some extent also at the MODIS scale. However, the air- borne retrieval shows how the field-scale ET variability is observable only at 10-m resolution, obtainable from satellite by means of thermal sharpening.

Moreover, the in-field variability observed at 10-m resolution, due in this case to the sparse configuration of olive trees, emphasizes the need for a two-source modeling scheme like DisALEXI for discriminating vegetation and soil contributions to the LST signal and to radiative and convective heat fluxes. Cammalleri et al. (2010) compare flux estimates from the TSEB applied to aircraft imagery over Castelvetrano with measurements collected with coherent scintillometer and eddy correlation systems deployed in an olive grove. Good results are obtained with the TSEB when vegetation clumping is properly accounted for (Fig. 10). The study of water use in fragmentized agricultural areas, like those surrounding Castelvetrano, will require the spatial and temporal resolutions that can only be obtained by combining thermal sharpening and data fusion techniques. 


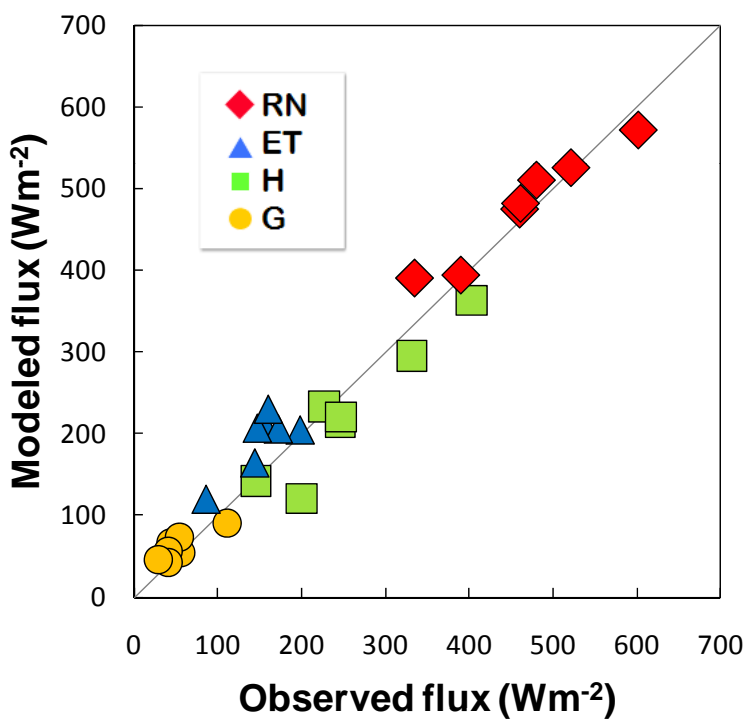

Fig. 10. Comparison between measured and modeled flux components obtained by applying the TSEB to aircraft imagery collected over an olive grove in Castelvetrano (Sicily) in an experiment described by Cammalleri et al. (2010). This plot summarizes data from Fig. 8 in Cammalleri et al, showing results obtained using the Goudriaan (1977) in-canopy wind profile scheme. Flux measurements represent an average of eddy correlation and coherent scintillometer data collected in-field.

\subsection{Africa: hydrologic decision support}

\subsubsection{Nile River Basin}

Another $10-\mathrm{km}$ resolution domain has been started over Africa for ET and drought monitoring, with a higher resolution 6-km assessment focused over the Nile River Basin in support of hydrologic modelling (see Fig. 11). The goal of this project is to combine hydrologic modelling (LDAS) driven by meteorological data from the Global Data Assimilation System (GDAS; Derber et al., 1991) or the European Centre for Medium-Range Weather Forecasts (ECMWF; Persson and Grazzini, 2007), with remotely sensed ET to provide improved information for water management along the Nile basin. LDAS soil moisture, runoff and ET estimates coupled with routing models will provide streamflow and lake level estimates to be used in a river forecasting system. The remote sensing ET from ALEXI will be used as an independent estimate of water diverted in support of irrigated agriculture within the basin. Employing the data fusion and Landsat thermal sharpening techniques described above, seasonal estimates of daily ET at the scales approaching that of individual irrigated parcels in heavily agricultural areas, such as in the Nile River Delta (Fig. 11). This will provide objective information about how water is being distributed across the complex irrigation networks that have developed along the river basin.

\section{Future work}

\subsection{Global applications}

Global implementation of ALEXI is a multi-sensor endeavour, and requires recovery of imagery from multiple geostationary platforms operated by many different countries. Fortunately, archives of global geostationary data are now being constructed to support global monitoring applications.

A 3-hourly, 10-km global dataset has been assembled by the US National Oceanic and Atmospheric Administration (NOAA) as part of the International Satellite Cloud Climatology Project (ISCCP) B1 data rescue project, instigated for the purpose of preserving a valuable global climatological data record (Knapp, 2008). The archive covers a period of record from 1983 to present, and includes data from the GOES satellites (covering the Americas), the Meteosat satellites, the Japanese Geostationary Meteorological Satellites (GMS) and Multi-Function Transport Satellites (MTSAT), and the Chinese Fen-yung (FY2) satellites. Preliminary investigations using 3-h datasets from the GEWEX Continental Scale International Project (GCIP) covering North America have confirmed that reasonable flux estimates can be retrieved by ALEXI using geostationary data at this temporal resolution, although the morning temperature rise computation is best facilitated by hourly data.

More recently, global LST and insolation datasets are being developed at $5-\mathrm{km}$ resolution by the Geoland 2 project under the European GMES (Global Monitoring for Environment and Security) initiative (Lacaze et al., 2010). Data currently are archived from 2008 to present at 3-hourly timesteps prior to June 2010 and hourly timesteps thereafter.

A pilot project generating global ALEXI flux maps using the Geoland2 LST and insolation data is currently underway for comparison with other global flux datasets generated under the GEWEX LandFlux initiative (Jimenez et al., 2011). This implementation will use LAI from MODIS and atmospheric data (primarily near surface wind speed and ABL lapse rate) from the NASA Global Modeling and Assimilation Office's (GMAO) Modern Era Retrospective Analysis for Research and Applications (MERRA; Bosilovich et al., 2008). The MERRA time period covers from 1979 to present, providing full 3-D atmospheric analyses (42 constant pressure levels; potential temperature) at a spatial resolution of $1.25^{\circ}$ every $3 \mathrm{~h}$. Additionally, 2-D surface fields (e.g. temperature and wind speed) are available at the same spatial resolution every hour. Table 2 summarizes input data sources for the proposed global ALEXI domain.

At high latitudes (exceeding $\pm 60^{\circ}$ ), the view zenith angle from geostationary platforms becomes too oblique to support LST retrieval, so a different approach will be required to supply ET estimates over land-surface area near the poles. One possible approach is to use the Dual-TimeDifference method described by Norman et al. (2000), exploiting the increased overpass frequency (multiple looks per 
Latent Heat

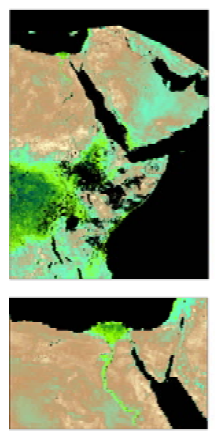

JULY
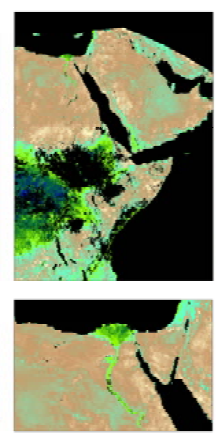

AUGUST
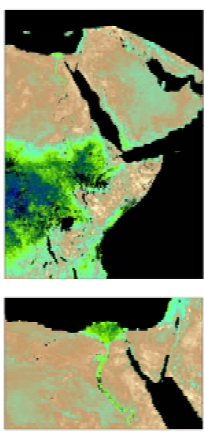

SEPTEMBER
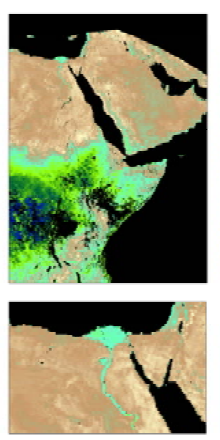

OCTOBER
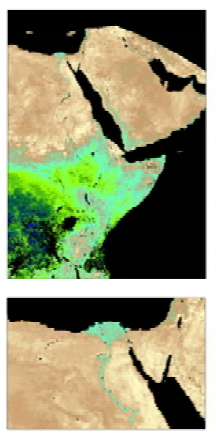

NOVEMBER

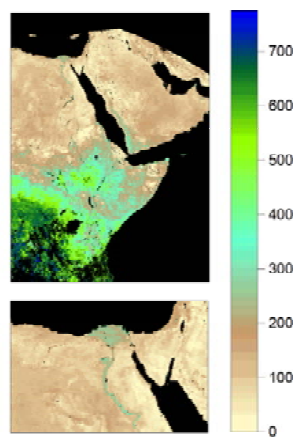

DECEMBER (Wm-2)
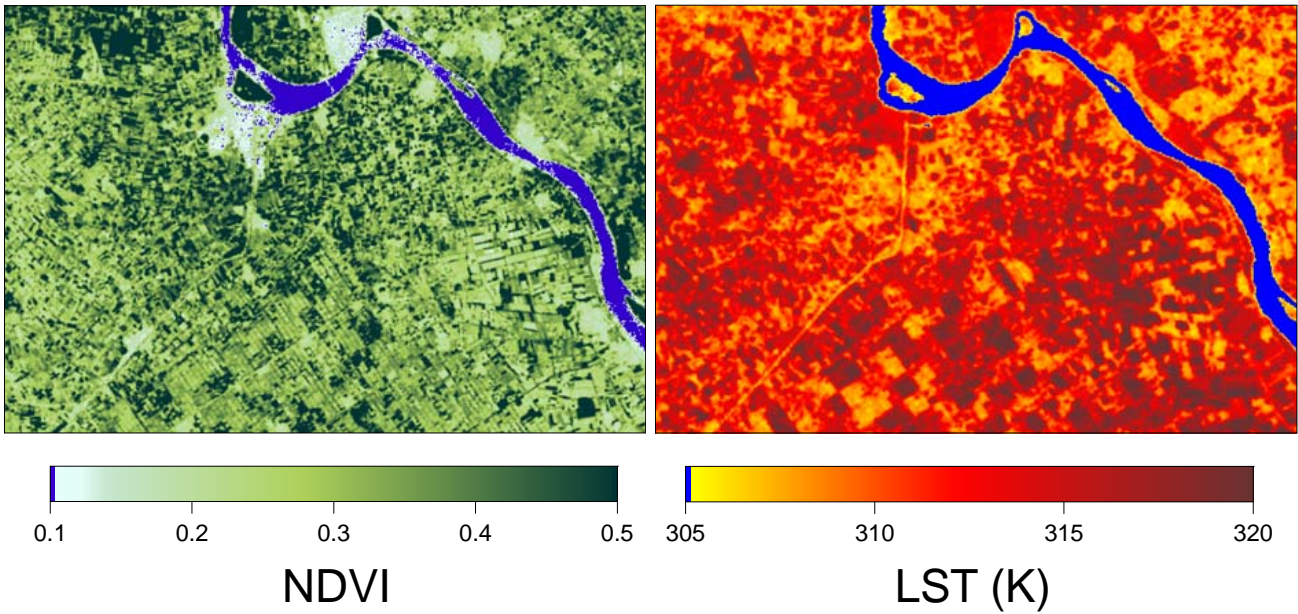

Fig. 11. Monthly composites of clear-sky latent heat flux (instantaneous, shortly before local noon) for 2008 over the Nile River Basin, generated at 6-km resolution by ALEXI using MSG land-surface products (top row). Blanked areas were perpetually cloud-covered. Also shown for resolution comparison are Landsat-7 maps of NDVI (30-m resolution) and LST (60-m) for a sub-region in the Nile Delta for 1 June 2008.

day) of polar orbiting thermal sensors like MODIS at high latitudes. A TIR-based snow energy balance modeling component, adapted from the work of Kongoli and Bland (2000), is under development to facilitate ALEXI application over snow-covered land-surfaces.

\subsection{Joint thermal-microwave data assimilation}

Incomplete cloud-clearing is a major source of error and noise in ALEXI flux determination, contributing to poor assessment of the morning surface temperature rise signal. Improvements to the ALEXI pre-processing infrastructure, including implementation of redundant input data-streams and improved cloud masks, are underway and should help to reduce noise in future reprocessing of ALEXI fluxes. Dependence on clear-sky conditions required for thermal-band LST retrieval, however, necessarily places a physical limitation (related to cloud climatology) on the frequency of sampling achievable with the ALEXI ET algorithm. Therefore, the optimal remote sensing approach may be a multi-band solution integrating thermal data with microwave (MW) based soil moisture information, which can be obtained under clear or cloudy skies.

Hain (2010) showed that joint assimilation of TIR ET/PET (from ALEXI) and MW soil moisture into the Noah LSM in NLDAS provides better soil moisture estimates than does either retrieval method (TIR or MW) in isolation. The two retrievals are quite complementary: TIR provides relatively high resolution and low temporal resolution (due to cloud cover) retrievals over a wide range of vegetation cover fraction, while MW provides relatively low spatial resolution and high temporal resolution (can see through clouds), but only over areas with sparse vegetation. Furthermore, MW retrievals are sensitive to soil moisture only in the soil surface layer $(0-5 \mathrm{~cm})$, while TIR provides information about soil moisture conditions integrated over the full root zone, reflected in the observed canopy temperature. The added value of TIR assimilation over MW alone is most significant in areas of moderate to dense vegetation cover $(>60 \%)$, where MW retrievals have little sensitivity to soil moisture at 
any depth. These conditions characterize much of the eastern US Joint assimilation of both TIR ET/PET and MW soil moisture into a prognostic LSM would serve to maximize both spatial and temporal sampling of surface moisture conditions, and would provide additional hydrologic information such as runoff, streamflow, and groundwater recharge.

\section{Conclusions}

We have presented a multi-sensor, multi-scale approach to mapping ET using thermal remote sensing data from both geostationary and polar-orbiting satellite platforms. This approach is physically based, requiring no subjective endmember selection as employed by many other thermal-based models, and can be fully automated for full global coverage. Use of time-differential TIR observations from geostationary satellites coupled to an ABL growth model improves robustness of continental-scale flux estimates to inevitable errors in LST retrieval and avoids the need for air temperature as a model input. Disaggregated flux fields using moderate and fine resolution TIR imagery from polar orbiting systems can be fused to generate daily ET maps at sub-field scales (10-m resolution).

This system has been used for applications in drought monitoring, irrigation management, and hydrologic decision support conducted in the US, Europe and Africa, with expansion to full global coverage underway. A new TIRbased Evaporative Stress Index (ESI), based on temporal anomalies in the actual-to-potential ET ratio, provides useful surface moisture proxy information without requiring precipitation data, and is well-suited for applications over areas lacking dense radar/raingauge networks. Diagnostic ET estimates from ALEXI/DisALEXI are also being used to evaluate more detailed hydrologic assessments generated with prognostic water balance models. Joint assimilation of TIR- and microwave-based soil moisture estimates will likely provide an optimal approach to hydrologic modelling.

Edited by: B. Su

\section{References}

Agam, N., Kustas, W. P., Anderson, M. C., Li, F., and Colaizzi, P. D.: Utility of thermal sharpening over Texas High Plains irrigated agricultural fields, J. Geophys. Res., 112, D19110, doi:19110.11029/12007JD008407, 2007a.

Agam, N., Kustas, W. P., Anderson, M. C., Li, F., and Neale, C. M. U.: A vegetation index based technique for spatial sharpening of thermal imagery, Remote Sens. Environ., 107, 545-558, $2007 \mathrm{~b}$.

Agam, N., Kustas, W. P., Anderson, M. C., Li, F., and Colaizzi, P. D.: Utility of thermal image sharpening for monitoring field-scale evapotranspiration over rainfed and irrigated agricultural regions, J. Geophys. Res. Lett., 35, L02402, doi:10.1029/2007GL032195, 2008.
Allen, R. G., Tasumi, M., and Trezza, R.: Satellite-based energy balance for mapping evapotranspiration with internalized calibration (METRIC) - Model, J. Irrig. Drainage Eng., 133(4), 380394, doi:10.1061/(ASCE)0733-9437(2007)133:4(380), 2007.

Anderson, M. C. and Kustas, W. P.: Thermal remote sensing of drought and evapotranspiration, Eos, Trans. AGU, 89, 233-234, 2008.

Anderson, M. C., Norman, J. M., Diak, G. R., Kustas, W. P., and Mecikalski, J. R.: A two-source time-integrated model for estimating surface fluxes using thermal infrared remote sensing, Remote Sens. Environ., 60, 195-216, 1997.

Anderson, M. C., Norman, J. M., Mecikalski, J. R., Torn, R. D., Kustas, W. P., and Basara, J. B.: A multi-scale remote sensing model for disaggregating regional fluxes to micrometeorological scales, J. Hydrometeor., 5, 343-363, 2004.

Anderson, M. C., Norman, J. M., Kustas, W. P., Li, F., Prueger, J. H., and Mecikalski, J. M.: Effects of vegetation clumping on two-source model estimates of surface energy fluxes from an agricultural landscape during SMACEX, J. Hydrometeorol., 6, 892-909, 2005.

Anderson, M. C., Kustas, W. P., and Norman, J. M.: Upscaling flux observations from local to continental scales using thermal remote sensing, Agron. J., 99, 240-254, 2007a.

Anderson, M. C., Norman, J. M., Mecikalski, J. R., Otkin, J. P., and Kustas, W. P.: A climatological study of evapotranspiration and moisture stress across the continental U.S. based on thermal remote sensing: II. Surface moisture climatology, J. Geophys. Res., 112, D11112, doi:11110.11029/12006JD007507, 2007b.

Anderson, M. C., Norman, J. M., Mecikalski, J. R., Otkin, J. P., and Kustas, W. P.: A climatological study of evapotranspiration and moisture stress across the continental U.S. based on thermal remote sensing: I. Model formulation, J. Geophys. Res., 112, D10117, doi:10110.11029/12006JD007506, 2007c.

Anderson, M. C., Norman, J. M., Kustas, W. P., Houborg, R., Starks, P. J., and Agam, N.: A thermal-based remote sensing technique for routine mapping of land-surface carbon, water and energy fluxes from field to regional scales, Remote Sens. Environ., 112, 4227-4241, 2008.

Anderson, M. C., Hain, C. R., Wardlow, B., Mecikalski, J. R., and Kustas, W. P.: Evaluation of a drought index based on thermal remote sensing of evapotranspiration over the continental U.S., J. Climate, in press, 2011.

Bosilovich, M. G., Chen, J.-L., Robertson, F. R., and Adler, R. F.: Evaluation of precipitation in reanalyses, J. Appl. Meteorol. Climatol., 47, 2279-2299, 2008.

Cammalleri, C., Anderson, M. C., Ciraolo, G., D’Urso, G., Kustas, W. P., La Loggia, G., and Minacapilli, M.: The impact of incanopy wind profile formulations on heat flux estimation in an open orchard using the remote sensing-based two-source model, Hydrol. Earth Syst. Sci., 14, 2643-2659, doi:10.5194/hess-142643-2010, 2010.

CHG (Confederación Hidrográfica del Guadalquivir): Esquema provisional de temas importantes. Plan de Gestión de Cuenca de la Demarcación Hidrográfica del Guadalquivir, http://www.chguadalquivir.es/export/sites/default/ portalchg/planHidrologicoDemarcacion/participacionPublica/ consultaPublica/ficheros/esquema_provisional_temas_ importantes_guadalquivir.zip 2008 (in Spanish).

Choi, M., Kustas, W. P., Anderson, M. C., Allen, R. G., Li, F., and 
Kjaersgaard, J. H.: An intercomparison of three remote sensingbased surface energy balance algorithms over a corn and soybean production region (Iowa, U.S.) during SMACEX, Agric. For. Meteorol., 149, 2082-2097, 2009.

Courault, D., Seguin, B., and Olioso, A.: Review on estimation of evapotranspiration from remote sensing data: From empirical to numerical modeling approaches, Irrigation and Drainage Systems, 19, 223-239, 2005.

Derber, J. C., Parrish, D. F., and Lord, S. J.: The New Global Operational Analysis System at the National-Meteorological-Center, Weather Forecast., 6, 538-547, 1991.

Detto, M., Montaldo, N., Albertson, J. D., Mancini, M., and Katul, G.: Soil moisture and vegetation controls on evapotranspiration in a heterogeneous Mediterranean ecosystem on Sardinia, Italy, Water Resour. Res., 42, W08419, doi:10.1029/2005WR004693, 2006.

Díaz, A., González-Dugo, M. P., Escuin, S., Mateos, L., Cano, F., Cifuentes, V., Tirado, J. L., and Oyonarte, N.: Irrigation water use monitoring at watershed scale using series of high-resolution satellite images, Remote Sensing for Agriculture, Ecosystems, and Hydrology XI, 7472, 74720E, doi:10.1117/1112.830371, 2009.

D'Urso, G.: Simulation and management of on-deman irrigation systems: a combined agrohydrological and remote sensing approach, Monographs, Wageningen, 173 pp., 2001.

Ganguly, S., Samanta, A., Schull, M. A., Shabanov, N. V., Milesi, C., Nemani, R. R., Knyazikhin, Y., and Myneni, R. B.: Generating vegetation leaf area index Earth system data record from multiple sensors. Part 2: Implementation, analysis and validation, Remote Sens. Environ., 112, 4318-4332, 2008.

Gao, F., Masek, J., Schwaller, M., and Hall, F. G.: On the blending of the Landsat and MODIS surface reflectance: predicting daily Landsat surface reflectance, IEE Trans. Geosci. Remote. Sens., 44, 2207-2218, 2006.

González-Dugo, M. P. and Mateos, L.: Spectral vegetation indices for benchmarking water productivity of irrigated cotton and sugarbeet crops, Agr. Water Manage., 95, 48-58, 2008.

Goudriaan, J.: Crop micrometeorology: a simulation study, Simulation Monographs, Wageningen, 249 pp., 1977.

Goward, S. N., Cruickshanks, G. D., and Hope, A. S.: Observed relation between thermal emission and reflected spectral radiance of a complex vegetated landscape, Remote Sens. Environ., 18, 137-146, 1985.

Hain, C. R.: Developing a dual assimilation approach for thermal infrared and passive microwave soil moisture retrievals, $\mathrm{PhD}$ Thesis, Dept. of Atmospheric Science, University of Alabama, 2010.

Hain, C. R., Mecikalski, J. R., and Anderson, M. C.: Retrieval of an available water-based soil moisture proxy from thermal infrared remote sensing. Part I: Methodology and validation, J. Hydrometeorology, 10, 665-683, 2009.

Hansen, M. C., Defries, R. S., Townshend, J. R. G., and Sohlberg, R.: Global land cover classification at $1 \mathrm{~km}$ spatial resolution using a classification tree approach, Int. J. Remote. Sens., 21, 1331-1364, 2000.

Hope, A. S. and McDowell, T. P.: The relationship between surface temperature and a spectral vegetation index of a tallgrass prairie: Effects of burning and other landscape controls, Int. J. Remote Sensing, 13, 2849-2863, 1992.
Jimenez, C., Prigent, C., Mueller, B., Seneviratne, S. I., McCabe, M. F., Wood, E. F., Rossow, W. B., Balsamo, G., Betts, A. K., Dirmeyer, P. A., Fisher, J. B., Jung, M., Kanamitsu, M., Reichle, R. H., Reichstein, M., Rodell, M., Sheffield, J., Tu, K., and Wang, K.: Global inter-comparison of 12 land surface heat flux estimates, J. Geophys. Res., in press, doi:10.1029/2010JD014545, 2011.

Kalma, J. D., McVicar, T. R., and McCabe, M. F.: Estimating land surface evaporation: A review of methods using remotely sensing surface temperature data, Survey Geophys., 29(4-5), 421469, doi:10.1007/s10712-10008-19037-z, 2008.

Knapp, K. R.: Scientific data stewardship of International Satellite Cloud Climatology Project B1 geostationary observations, J. Appl. Remote Sensing, 2, 023548, doi:10.1117/1.3043461, 2008.

Kongoli, C. E. and Bland, W. L.: Long-term snow depth simulations using a modified atmosphere-land exchange model, Agric. For. Meteorol., 104, 273-287, 2000.

Kustas, W. P. and Anderson, M. C.: Advances in thermal infrared remote sensing for land surface modeling, Agric. For. Meteorol., 149, 2071-2081, 2009.

Kustas, W. P. and Norman, J. M.: Evaluation of soil and vegetation heat flux predictions using a simple two-source model with radiometric temperatures for partial canopy cover, Agric. For. Meteorol., 94, 13-29, 1999.

Kustas, W. P. and Norman, J. M.: A two-source energy balance approach using directional radiometric temperature observations for sparse canopy covered surfaces, Agronomy J., 92, 847-854, 2000.

Kustas, W. P., Diak, G. R., and Norman, J. M.: Time difference methods for monitoring regional scale heat fluxes with remote sensing, Land Surface Hydrology, Meteorology, and Climate: Observations and Modeling, 3, 15-29, 2001.

Kustas, W. P., Norman, J. M., Anderson, M. C., and French, A. N.: Estimating subpixel surface temperatures and energy fluxes from the vegetation index-radiometric temperature relationship, Remote Sens. Environ., 85, 429-440, 2003.

Lacaze, R., Balsamo, G., Baret, F., Bradley, A., Calvet, J.-C., Camacho, F., D'Andrimont, R., Freitas, S. C., Makhmara, H., Naeimi, V., Pacholczyk, P., Poilvé, H., Smets, B., Tansey, K., Trigo, I. F., Wagner, W., and Weiss, M.: Geoland 2 - Towards an operational GMES land monitoring core service; First results of the biogeophysical parameter core mapping service, ISPRS TC VII Symposium - 100 Years ISPRS, Vienna, Austria,, IAPRS, 354359, 2010.

McNaughton, K. G. and Spriggs, T. W.: A mixed-layer model for regional evaporation, Bound.-Lay. Meteorol., 74, 262-288, 1986.

Mecikalski, J. M., Diak, G. R., Anderson, M. C., and Norman, J. M.: Estimating fluxes on continental scales using remotelysensed data in an atmosphere-land exchange model, J. Applied Meteorol., 38, 1352-1369, 1999.

Merlin, O., Duchemin, B., Hagolle, O., Jacob, F., Coudert, B., Chehbouni, A., Dedieu, G., Garatuza, J., and Kerr, Y.: Disaggregation of MODIS surface temperature over an agricultural area using a time series of Formosat-2 images, Remote Sens. Environ., 114, 2500-2512, 2010.

Mesinger, F., DiMego, G., Kalnay, E., Mitchell, K. E., Shafran, P. C., Ebisuzaki, W., Jovic, D., Woollen, J., Rogers, E., Berbery, 
E. H., Ek, M. B., Fan, Y., Grumbine, R., Higgins, W., Li, H., Lin, Y., Manikin, G., Parrish, D., and Shi, W.: North American Regional Reanalysis, B. Am. Meteorol. Soc., 87, 343-360, 2006.

Minacapilli, M., Iovino, M., and D'Urso, G.: A distributed agrohydrological model for irrigation water demand assessment, Agr. Water Manage., 95, 123-132, 2008.

Minacapilli, M., Agnese, C., Blanda, F., Cammalleri, C., Ciraolo, G., D’Urso, G., Iovino, M., Pumo, D., Provenzano, G., and Rallo, G.: Estimation of actual evapotranspiration of Mediterranean perennial crops by means of remote-sensing based surface energy balance models, Hydrol. Earth Syst. Sci., 13, 1061-1074, doi:10.5194/hess-13-1061-2009, 2009.

Mitchell, K. E., Lohmann, D., Houser, P. R., Wood, E. F., Schaake, J. C., Robock, A., Cosgrove, B. A., Sheffield, J., Duan, Q., Luo, L., Higgins, R. W., Pinker, R. T., Tarpley, J. D., Lettenmaier, D. P., Marshall, C. H., Entin, J. K., Pan, M., Shi, W., Koren, V., Meng, J., Ramsay, B. H., and Bailey, A. A.: The multi-institution North American Land Data Assimilation System (NLDAS): Utilizing multiple GCIP products and partners in a continental distributed hydrological modeling system, J. Geophys. Res., 190, D07S90, doi:10.1029/2003JD003823, 2004.

Moran, M. S.: Thermal infrared measurement as an indicator of plant ecosystem health, in: Thermal Remote Sensing in Land Surface Processes, edited by: Quattrochi, D. A. and Luvall, J., Taylor and Francis, 257-282, 2003.

Norman, J. M., Kustas W. P., and Humes, K. S.: A two-source approach for estimating soil and vegetation energy fluxes from observations of directional radiometric surface temperature, Agr. For. Meteorol., 77, 263-293, 1995.

Norman, J. M., Kustas, W. P., Prueger, J. H., and Diak, G. R.: Surface flux estimation using radiometric temperature: a dual temperature difference method to minimize measurement error, Water Resour. Res., 36, 2263-2274, 2000.

Norman, J. M., Anderson, M. C., Kustas, W. P., French, A. N., Mecikalski, J. R., Torn, R. D., Diak, G. R., Schmugge, T. J., and Tanner, B. C. W.: Remote sensing of surface energy fluxes at $10^{1}-\mathrm{m}$ pixel resolutions, Water Resour. Res., 39(8), 1221, doi:10.1029/2002WR001775, 2003.

Persson, A. and Grazzini, F.: User guide to ECMWF forecast products Version 4.0, Meteorological Bulletin M3.2, European Centre for Medium Range Weather Forecasts, Reading, UK, 161 pp., 2007.
Priestley, C. H. B. and Taylor, R. J.: On the assessment of surface heat flux and evaporation using large-scale parameters, Mon. Weather Rev., 100, 81-92, 1972.

Rana, G. and Katerji, N.: Measurement and estimation of actual evapotranspiration in the field under Mediterranean climate: a review, Eur. J. Agron., 13, 125-153, 2000.

Sánchez, J. M., Scavone, G., Caselles, V., Valor, E., Copertino, V. A., and Tedesca, V.: Monitoring daily evapotranspiration at a regional scale from Landsat-TM and ETM+ data: Application to the Basilicata region, J. Hydrol., 351, 58-70, 2008.

Skamarock, W. C., Klemp, J. B., Dudhia, J., Gill, D. O., Barker, M., Wang, W., and Powers, J. G.: A description of the Advanced Research WRF Version 2, NCAR Tech Notes-468+STR, 2005.

Smith, R. C. G. and Choudhury, B. J.: Analysis of normalized difference and surface temperature observations over southeastern Australia, Int. J. Remote Sensing, 12, 2021-2044, 1991.

Sobrino, J. A., Jiménez-Muñoz, J. C., Zarco-Tejada, P. J., SepulcreCantó, G., de Miguel, E., Sòria, G., Romaguera, M., Julien, Y., Cuenca, J., Hidalgo, V., Franch, B., Mattar, C., Morales, L., Gillespie, A., Sabol, D., Balick, L., Su, Z., Jia, L., Gieske, A., Timmermans, W., Olioso, A., Nerry, F., Guanter, L., Moreno, J., and Shen, Q.: Thermal remote sensing from Airborne Hyperspectral Scanner data in the framework of the SPARC and SEN2FLEX projects: an overview, Hydrol. Earth Syst. Sci., 13, 2031-2037, doi:10.5194/hess-13-2031-2009, 2009.

Svoboda, M., LeComte, D., Hayes, M., Heim, R., Gleason, K., Angel, J., Rippey, B., Tinker, R., Palecki, M., Stooksbury, D., Miskus, D., and Stephens, S.: The Drought Monitor, B. Am. Meteorol. Soc., 83, 1181-1190, 2002.

Trigo, I. F., DaCamara, C. C., Viterbo, P., Roujean, J.-L., Olesen, F., Barroso, C. F., Camacho-de Coca, F., Carrer, D., Freitas, S. C., García-Haro, J., Geiger, B., Gellens-Meulenberghs, F., Ghilain, N., Meliá, J., Pessanha, L., Siljamo, N., and Arboleda, A.: The Satellite Application Facility on Land Surface Analysis, Int. J. Remote Sensing, in press, 2011.

van der Kwast, J., Timmermans, W., Gieske, A., Su, Z., Olioso, A., Jia, L., Elbers, J., Karssenberg, D., and de Jong, S.: Evaluation of the Surface Energy Balance System (SEBS) applied to ASTER imagery with flux-measurements at the SPARC 2004 site (Barrax, Spain), Hydrol. Earth Syst. Sci., 13, 1337-1347, doi:10.5194/hess-13-1337-2009, 2009. 